\title{
Jet Instability over Smooth, Corrugated, and Realistic Bathymetry
}

\author{
J. H. LACASCE \\ Department of Geosciences, University of Oslo, Oslo, Norway \\ J. ESCARTIN \\ Institut de Physique du Globe de Paris, Paris, France \\ ERIC. P. Chassignet AND XiaObiaO Xu \\ Florida State University, Tallahassee, Florida
}

(Manuscript received 30 June 2018, in final form 20 November 2018)

\begin{abstract}
The stability of a horizontally and vertically sheared surface jet is examined, with a focus on the vertical structure of the resultant eddies. Over a flat bottom, the instability is mixed baroclinic/barotropic, producing strong eddies at depth that are characteristically shifted downstream relative to the surface eddies. Baroclinic instability is suppressed over a large slope for retrograde jets (with a flow antiparallel to topographic wave propagation) and to a lesser extent for prograde jets (with flow parallel to topographic wave propagation), as seen previously. In such cases, barotropic (lateral) instability dominates if the jet is sufficiently narrow. This yields surface eddies whose size is independent of the slope but proportional to the jet width. Deep eddies still form, forced by interfacial motion associated with the surface eddies, but they are weaker than under baroclinic instability and are vertically aligned with the surface eddies. A sinusoidal ridge acts similarly, suppressing baroclinic instability and favoring lateral instability in the upper layer. A ridge with a 1-km wavelength and an amplitude of roughly $10 \mathrm{~m}$ is sufficient to suppress baroclinic instability. Surveys of bottom roughness from bathymetry acquired with shipboard multibeam echo sounding reveal that such heights are common beneath the Kuroshio, the Antarctic Circumpolar Current, and, to a lesser extent, the Gulf Stream. Consistent with this, vorticity and velocity cross sections from a $1 / 50^{\circ} \mathrm{HYCOM}$ simulation suggest that Gulf Stream eddies are vertically aligned, as in the linear stability calculations with strong topography. Thus, lateral instability may be more common than previously thought, owing to topography hindering vertical energy transfer.
\end{abstract}

\section{Introduction}

In many extratropical regions, the vertical structure of time-varying horizontal velocities can be captured with a single EOF (Wunsch 1997; de La Lama et al. 2016). This has numerous applications, for example, in projecting satellite-derived surface data downward in the water column. The EOF has a characteristic shape, decaying monotonically from the surface to a value near zero at the bottom. The structure differs from the traditional first baroclinic mode, which crosses zero at middepth and has flow at the bottom, but closely resembles the first "surface mode," the gravest baroclinic mode obtained with zero horizontal velocity at the bottom (de La Lama et al. 2016; LaCasce 2017).

\footnotetext{
Corresponding author: J. H. LaCasce, j.h.lacasce@geo.uio.no
}

The prevalence of the surface mode is due to bottom topography. With a sufficiently steep slope, the depthvarying baroclinic modes adjust to have near-zero bottom velocities (Rhines 1970; Charney and Flierl 1981). At the same time, the barotropic mode, present with a flat bottom, is replaced by topographic waves. With realistic stratification, this modal shift occurs even with modest bottom slopes, of order $10^{-5}-10^{-4}$ (LaCasce 2017). Topographic gradients, calculated over separations of $100 \mathrm{~km}$, are at least this large over much of the ocean. Similar modal changes occur in the presence of bottom roughness, if the topographic heights are large enough (Samelson 1992; Bobrovich and Reznik 1999). As such, it is probably more sensible to discuss eddy vertical structure in terms of surface modes and topographic waves than with conventional baroclinic and barotropic modes. 
The preceding comments apply in the absence of a mean flow and are thus more relevant to the ocean interior than near boundary currents like the Gulf Stream. Vertical modes can differ substantially with a mean flow and moreover are often unstable (Pedlosky 1987). If the flow has only vertical shear, the most unstable mode converts available potential energy to eddy kinetic energy (Charney 1947; Eady 1949; Phillips 1954). Such baroclinic instability is thought to be widespread in the ocean, as potential energy greatly exceeds kinetic (Gill et al. 1974; Smith 2007; Tulloch et al. 2011).

However, all ocean currents also possess lateral shear, permitting barotropic (hereafter "lateral") instability, in which the conversion of mean to eddy kinetic energy dominates. Lateral instability is somewhat less familiar than baroclinic, owing to the analytical complexity of studying laterally sheared currents (Kuo 1949). But the meandering and eddy formation exhibited by currents like the Gulf Stream is qualitatively similar to that seen in single-layer models where only lateral instability can occur (Flierl et al. 1987; Poulin and Flierl 2003).

Baroclinic instability is also strongly affected by bottom topography, and in sometimes nonintuitive ways (Blumsack and Gierasch 1972; Hart 1975; Tang 1976; Mysak and Schott 1977; Mechoso 1980; Ikeda 1983; Pichevin 1998; Isachsen 2011; Ribstein and Zeitlin 2013; Gula and Zeitlin 2014). A slope with isobaths parallel to the mean flow can suppress baroclinic instability when the shallower water lies to the left of the current (in the Northern Hemisphere). However, the flow is not stabilized if the shallower water lies to the right. Rather, the growth rates are reduced and the resulting eddies are smaller. Thus, there is an asymmetry between flows that are "retrograde" relative to the topographic wave propagation (the Gulf Stream, Kuroshio, and Agulhas) and "prograde" (the Norwegian, Greenland, Oyashio, and Leeuwin Currents). The situation is more complicated still when the flow is not parallel to the isobaths, as the slope can destabilize the flow (Chen and Kamenkovich 2013).

Bottom roughness affects baroclinic instability similarly. Introducing one-dimensional roughness (a sinusoidal ridge) to a two-layer Phillips model yields slower growth rates and smaller-scale eddies (Benilov 2001). The effect depends on the ridge orientation; growth suppression is greatest when the ridges are parallel to the mean flow, but no suppression occurs when they are perpendicular (as the perturbation velocity perpendicular to the mean flow is then parallel to the isobaths). In addition, when the topographic wavelength is much smaller than deformation scale, the stabilizing effect is independent of the ridge wavelength and depends only on the topographic height. Thus, small-scale topographic features, unresolved in most ocean models, could potentially affect current stability. Similar effects are found in the (continuously stratified) Eady model with ridges (Vanneste 2003).

The aforementioned studies treat mean flows with only vertical shear. Lateral shear introduces additional effects, but these have generally been studied numerically (e.g., Orlanski 1969; Mechoso and Sinton 1981; Poulin and Flierl 2003; Brink 2012). The conclusion is often that the instability is "mixed": partly baroclinic and partly barotropic (e.g., Semtner and Mintz 1977). In general, though, less attention has been paid to the vertical structure of the unstable eddies.

Hereafter we use a linear two-layer model to study the stability of a surface-trapped jet over a slope. The focus is on the vertical structure of the fastest-growing modes, using oceanographically relevant parameters. As seen before, the slope suppresses baroclinic instability. Then, if the jet is narrow enough, lateral instability in the upper layer dominates. A sinusoidal ridge has a similar effect, if it is sufficiently high.

To see if such topographic heights occur, we examine multibeam bathymetry surveys of the seafloor beneath the Gulf Stream, Kuroshio, and the Antarctic Circumpolar Current (ACC). The results suggest the bottom is indeed sufficiently rough to affect the vertical energy transfer. Then we examine eddies in a high-resolution Hybrid Coordinate Ocean Model (HYCOM) simulation of the North Atlantic. The eddies generated in the Gulf Stream are surface intensified and decay monotonically with depth, without exhibiting the characteristic tilting expected for baroclinic instability. Thus, lateral instability may be important in currents like the Gulf Stream, producing mostly surface-trapped eddies.

\section{Methods}

\section{a. Linear stability analysis}

For the stability study, we employ a quasigeostrophic (QG) two-layer model. The model's relative simplicity facilitates exploring parameter dependencies but excludes possibly important features like fronts. The nondimensional equations, linearized about a zonal mean flow, are (Pedlosky 1987):

$$
\begin{aligned}
& \left(\frac{\partial}{\partial t}+U_{1} \frac{\partial}{\partial x}\right) q_{1}+q_{1 s y} \frac{\partial}{\partial x} \psi_{1}=0, \quad \text { and } \\
& \left(\frac{\partial}{\partial t}+U_{2} \frac{\partial}{\partial x}\right) q_{2}+q_{2 s y} \frac{\partial}{\partial x} \psi_{2}=0,
\end{aligned}
$$

where

$$
q_{i} \equiv \nabla^{2} \psi_{i}+F_{i}\left(\psi_{3-i}-\psi_{i}\right)
$$

are the layer potential vorticities. The $F_{1}=f_{0}^{2} L^{2} /\left(g^{\prime} H_{1}\right)$ is the Burger number in the upper layer and $F_{2}=\delta F_{1}$ 
( $\left.\delta=H_{1} / H_{2}\right)$ is that in the lower layer. We take $L=L_{w}$, the lateral scale of the jet; as such, $F_{1}$ is the squared ratio of the jet width to the deformation radius in the upper layer. Bottom friction is neglected, as this produced relatively weak effects for realistic values of the (Ekman) drag coefficient.

The $q_{i s y}$ are the mean potential vorticity (PV) gradients:

$$
\begin{aligned}
& q_{1 s y}(y)=F_{1}\left(U_{1}-U_{2}\right)-\frac{\partial^{2} U_{1}}{\partial y^{2}}, \\
& q_{2 s y}(y)=F_{2}\left(U_{2}-U_{1}\right)-\frac{\partial^{2} U_{2}}{\partial y^{2}}+\alpha .
\end{aligned}
$$

The bottom slope, given by $h=\alpha y$, is oriented parallel to the mean flow. We thereby neglect the additional complications introduced by having nonparallel bathymetry (Chen and Kamenkovich 2013). We also neglect the $\beta$ effect by restricting attention to the $f$ plane. These assumptions are reasonable for many boundary currents, being surface trapped and parallel to the isobaths, but are less appropriate for a separated current like the Gulf Stream.

The nondimensional slope parameter is

$$
\alpha=\frac{\beta_{t} L_{w}}{\operatorname{Ro} H_{2}}
$$

where $\beta_{t}$ is the dimensional slope and $\operatorname{Ro}=U /\left(f_{0} L_{w}\right)$ is the Rossby number based on the jet width. Assuming the latter is of order $50 \mathrm{~km}$ (a realistic value for the Gulf Stream; Halkin and Rossby 1985), that the velocity scale is $0.5 \mathrm{~m} \mathrm{~s}^{-1}$, and that the lower layer depth is $4000 \mathrm{~m}$, a $1 \%$ slope yields $\alpha \approx 1$.

We use energy diagnostics to diagnose the different types of instability. Multiplying Eq. (1) by $\delta \psi_{1} /(1+\delta)$ and Eq. (2) by $\psi_{2} /(1+\delta)$ and adding the results yields the following:

$$
\begin{aligned}
\frac{d}{d t} \mathrm{TE} & =-\frac{\delta}{1+\delta} \iint U_{1} v_{1} q_{1} d A-\frac{1}{1+\delta} \iint U_{2} v_{2} q_{2} d A \\
& =\frac{\delta}{1+\delta} \iint U_{1} v_{1} \frac{\partial}{\partial y} u_{1} d A+\frac{1}{1+\delta} \iint U_{2} v_{2} \frac{\partial}{\partial y} u_{2} d A+F \iint\left(U_{1}-U_{2}\right) v_{2} \psi_{1} d A
\end{aligned}
$$

Here TE, the total perturbation energy, is the sum of the kinetic and potential energies:

$$
\begin{aligned}
\mathrm{TE}= & \frac{\delta}{2(1+\delta)} \iint\left(u_{1}^{2}+v_{1}^{2}\right) d A+\frac{1}{2(1+\delta)} \iint\left(u_{2}^{2}+v_{2}^{2}\right) d A \\
& +\frac{F}{2} \iint\left(\psi_{2}-\psi_{1}\right)^{2} d A,
\end{aligned}
$$

with $F \equiv f_{0}^{2} L^{2} /\left[g^{\prime}\left(H_{1}+H_{2}\right)\right]$. Thus, the perturbation energy changes in response to horizontal momentum fluxes in the upper and lower layers and to the meridional thickness flux. The last, proportional to the meridional density flux, is often associated with baroclinic instability while the first two reflect lateral instability in their respective layers.

The stability problem involves inserting wavelike solutions, $\psi_{i}=\hat{\psi}_{i}(y) \exp [i k(x-c t)]$, into Eqs. (1) and (2), which can then be rewritten:

$$
\begin{gathered}
{\left[U_{1}\left(\frac{\partial^{2}}{\partial y^{2}}-k^{2}-F_{1}\right)+q_{1 s y}\right] \hat{\psi}_{1}+U_{1} F_{1} \hat{\psi}_{2}} \\
=c\left(\frac{\partial^{2}}{\partial y^{2}}-k^{2}-F_{1}\right) \hat{\psi}_{1}+c F_{1} \hat{\psi}_{2}, \quad \text { and } \\
U_{2} F_{2} \hat{\psi}_{1}+\left[U_{2}\left(\frac{\partial^{2}}{\partial y^{2}}-k^{2}-F_{2}\right)+q_{2 s y}\right] \hat{\psi}_{2} \\
=c F_{2} \hat{\psi}_{1}+c\left(\frac{\partial^{2}}{\partial y^{2}}-k^{2}-F_{2}\right) \hat{\psi}_{2} .
\end{gathered}
$$

This yields a generalized eigenvalue problem. Solutions were obtained in MATLAB, using a Chebyshev grid in $y$ and differentiation as specified by Trefethen (2001). The code was tested against the Phillips (1954) solution, with a uniform surface flow and a flat or sloping bottom (Mysak and Schott 1977). The theoretical and numerical growth rates agreed within the errors.

For the mean flow, we employ a Bickley jet (e.g., Bickley 1937; Maslowe 1991; Bouchut et al. 2011; Lambaerts et al. 2012):

$$
U_{1}=U_{0} \operatorname{sech}^{2}\left(\frac{y}{L}\right) .
$$

The amplitude and width are both set to 1.0, in line with the nondimensionalization. We will focus on a surfacetrapped flow and set $U_{2}=0$. Additional effects can be found with nonzero deep flow (or even an initially barotropic flow; e.g., Bouchut et al. 2011), but a surface flow is sufficient for the present purposes. Last, we set the layer depth ratio, $\delta=1 / 4$, representative of the interior ocean.

The flow geometry is sketched in Fig. 1. The domain is a channel, with $\psi_{1}=\psi_{2}=0$ at the channel walls, at $y= \pm L_{w}$. We set $L_{w}=5$, so that the channel is five times wider than the jet. Tests showed that unstable growth was suppressed for $L_{w}<2.5$ (see below), and using $L_{w}=5$ was sufficient to avoid this. Solutions were well resolved with 200 grid points in the meridional direction. The channel is open in the zonal direction, but fractional 


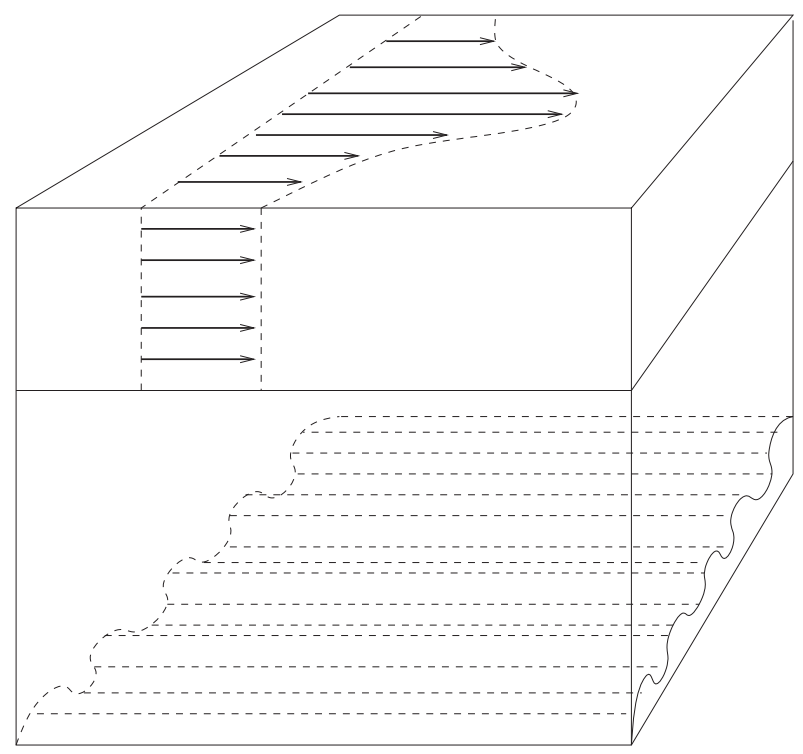

FIG. 1. The surface Bickley jet in two layers over a corrugated slope.

values of the zonal wavenumber are used so that the solutions are not necessarily zonally periodic.

In section $3 \mathrm{a}$, we add a one-dimensional (sinusoidal) bottom ridge. The isobaths are parallel to the surface flow, so that $h=h(y)$ (Fig. 1). As noted, this orientation yields the maximum stabilizing effect (Benilov 2001). With the ridge and zero mean flow in the lower layer, the lower layer PV gradient is

$$
q_{2 s y}=-F_{2} U_{1}+\alpha+\frac{\partial}{\partial y} h .
$$

\section{b. Bathymetry}

In section $3 \mathrm{~b}$, we present observations of bottom roughness. Seafloor morphology is shaped by the interaction of volcanic, tectonic, sedimentary, and erosion processes. In the deep ocean, the oceanic crust is formed along ridges where volcanic and tectonic processes produce abyssal hills that tend to be parallel to the ridge axis (e.g., Menard and Mammerickx 1967; Rona et al. 1974). The shape, amplitude, and length scales vary depending on the spreading rate of the plates (e.g., Goff and Arbic 2010). The texture is significantly modified by erosion and sedimentary processes (Moore et al. 1999; Rona et al. 1974; Jaroslow and Tucholke 1994; Dubois and Mitchell 2012) and by late volcanism such as the emplacement of ubiquitous seamounts (Wessel 2001).

Accurate and detailed seafloor morphology can be obtained from shipborne multibeam echo-sounding data, with spatial resolutions of $100 \mathrm{~m}$ or better. Multibeam data are publicly available for $8.3 \%$ of the global ocean through the Global Multiresolution Topography (GMRT) Synthesis (Ryan et al. 2009; www.gmrt.org), in addition to published datasets in the literature. We have selected areas that have sufficient GMRT bathymetric coverage beneath the paths of the Gulf Stream, Kuroshio, and ACC. For the Kuroshio, the GMRT data are complemented with data from the Hydrographic and Oceanographic Department, Japan Coast Guard, and JAMSTEC (2011) of Japan. For our roughness measurements, we selected bathymetry over boxes with sufficient data coverage and gridded with a horizontal spatial resolution of 50-60 m.

The areas used from the three currents are shown in Table 1. The center latitude and longitude of each area are given, as are the grid resolution, surface area covered, and average depth. For all grids we eliminated areas outside the current tracks. For the Kuroshio, we used the envelope of tracks given in Ambe et al. (2004), while we used those of Moore et al. (1999) for the ACC and those of Renault et al. (2016) for the Gulf Stream.

We calculate the RMS topographic heights using data within a chosen horizontal distance from the area center. We used search radii of 500 and $5000 \mathrm{~m}$, to evaluate the roughness over scales of 1 and $10 \mathrm{~km}$. Table 1 lists the average RMS values for each grid, with both radii.

\section{c. HYCOM simulation}

Assessing the vertical structure of eddies from observations is challenging because of the sparseness of the latter. A numerical model lends itself well to this, as full 3D fields can be obtained at any given time. In section $3 c$, we examine the eddies in a high-resolution simulation of the North Atlantic using HYCOM, run previously by Chassignet and Xu (2017). HYCOM employs a hybrid vertical coordinate, which shifts from isopycnal in the open ocean, to terrain-following in shallow regions, and to fixed pressure levels in the surface layer or in unstratified regions (Bleck 2002; Chassignet et al. 2003). The present simulation encompasses most of the North Atlantic, with a domain that extends from $28^{\circ} \mathrm{S}$ to $80^{\circ} \mathrm{N}$. There is no inflow or outflow at these boundaries, and the model temperature, salinity and isopycnal depths are restored to climatological values at each. Further details are given by Chassignet and Xu (2017) and references therein.

The simulation was one of three of the North Atlantic, run with horizontal resolutions of $1 / 12^{\circ}, 1 / 25^{\circ}$, and $1 / 50^{\circ}$ (yielding grid spacings of roughly 6,3 , and $1.5 \mathrm{~km}$ in the Gulf Stream region). The model topography is based on a $2^{\prime}$ resolution dataset, which is appropriate for the $1 / 12^{\circ}$ model. The topography for the higher-resolution runs was linearly interpolated from the $2^{\prime}$ dataset. 
TABLE 1. The RMS topographic heights obtained from shipboard multibeam echo-sounding data, beneath the Gulf Stream (GS), Kuroshio (Kuro), and the ACC. Listed are the longitude and latitude of the search areas, the area surveyed, the mean depth, and the RMS topographic heights for 500-m and 5-km search radii. The (publicly available) bathymetry data were obtained online (www.gmrt.org). Data for the sites for the Kuroshio marked with asterisks were obtained from the Hydrographic and Oceanographic Department, Japan Coast Guard, and JAMSTEC (2011).

\begin{tabular}{|c|c|c|c|c|c|c|c|}
\hline Site & Lon $\left(^{\circ}\right)$ & Lat $\left(^{\circ}\right)$ & Resolution (m) & Area $\left(\mathrm{km}^{2}\right)$ & Depth (m) & $\mathrm{RMS}_{500 \mathrm{~m}}(\mathrm{~m})$ & $\mathrm{RMS}_{5 \mathrm{~km}}(\mathrm{~m})$ \\
\hline $\mathrm{ACC}$ & 10.00 & -52.75 & 37 & 13877.8 & -3126 & 45.8 & 276.1 \\
\hline $\mathrm{ACC}$ & 14.50 & -50.40 & 78 & 39168.5 & -3329 & 37.6 & 188.0 \\
\hline $\mathrm{ACC}$ & 19.50 & -50.40 & 78 & 16942.6 & -3703 & 37.4 & 173.4 \\
\hline $\mathrm{ACC}$ & 24.50 & -50.40 & 78 & 25017.1 & -3793 & 39.8 & 187.1 \\
\hline $\mathrm{ACC}$ & -67.50 & -61.00 & 59 & 18915.1 & -3561 & 32.3 & 124.4 \\
\hline ACC & -97.50 & -62.50 & 56 & 8829.1 & -5001 & 9.1 & 29.9 \\
\hline $\mathrm{ACC}$ & 145.50 & -59.00 & 63 & 4438.5 & -3086 & 33.8 & 116.1 \\
\hline $\mathrm{ACC}$ & 148.25 & -56.75 & 33 & 2153.3 & -3320 & 39.3 & 107.9 \\
\hline $\mathrm{ACC}$ & -150.00 & -57.50 & 33 & 4582.1 & -3057 & 30.0 & 73.7 \\
\hline $\mathrm{ACC}$ & 162.50 & -58.00 & 65 & 19444.5 & -4291 & 21.6 & 101.6 \\
\hline $\mathrm{ACC}$ & 167.50 & -61.50 & 58 & 4564.7 & -3276 & 32.5 & 134.9 \\
\hline $\mathrm{ACC}$ & -170.00 & -61.05 & 59 & 30203 & -3892 & 34.8 & 157.2 \\
\hline $\mathrm{ACC}$ & 171.30 & -61.15 & 29 & 3560.7 & -4041 & 33.1 & 139.8 \\
\hline $\mathrm{ACC}$ & 177.35 & -62.00 & 57 & 17521.9 & -4112 & 32.1 & 139.7 \\
\hline $\mathrm{ACC}$ & -32.79 & -48.89 & 80 & 19329.9 & -4977 & 25.6 & 137.7 \\
\hline $\mathrm{ACC}$ & -50.75 & -54.75 & 70 & 11191.8 & -3739 & 25.4 & 107.4 \\
\hline $\mathrm{ACC}$ & -51.70 & -55.39 & 35 & 5267.8 & -3785 & 24.0 & 98.4 \\
\hline $\mathrm{ACC}$ & -61.00 & -58.50 & 32 & 21204.6 & -3669 & 31.3 & 162.8 \\
\hline Kuro & 133.25 & 29.75 & 53 & 3899.5 & -4221 & 20.8 & 112.0 \\
\hline Kuro & 136.00 & 30.50 & 53 & 14355.5 & -4213 & 13.2 & 70.7 \\
\hline Kuro & 139.65 & 32.20 & 52 & 7501.9 & -1439 & 28.0 & 121.4 \\
\hline Kuro & 142.00 & 35.10 & 50 & 12045.8 & -5293 & 30.7 & 184.3 \\
\hline Kuro & 140.50 & 35.10 & 253 & 14892.3 & -4378 & 27.9 & $185.3^{*}$ \\
\hline Kuro & 140.50 & 35.10 & 126 & 66826.7 & -4816 & 30.0 & $181.7^{*}$ \\
\hline GS & -58.00 & 40.25 & 47 & 605.3 & -5156 & 3.3 & 5.9 \\
\hline GS & -62.00 & 39.00 & 47 & 32644.7 & -4796 & 13.2 & 73.3 \\
\hline GS & -66.00 & 38.25 & 48 & 43365.6 & -4832 & 3.6 & 19.2 \\
\hline GS & -69.50 & 37.50 & 48 & 25643.2 & -4269 & 3.1 & 18.5 \\
\hline GS & -73.00 & 37.00 & 49 & 25869.5 & -3583 & 3.8 & 27.9 \\
\hline GS & -73.50 & 35.00 & 50 & 20927.2 & -2629 & 11.3 & 83.8 \\
\hline GS & -77.00 & 33.00 & 51 & 7828.6 & -1638 & 9.2 & 65.6 \\
\hline GS & -78.50 & 31.00 & 52 & 1842.4 & -634 & 2.7 & 13.8 \\
\hline
\end{tabular}

Gulf Stream penetration and the recirculation gyres were found to improve greatly with $1 / 50^{\circ}$ resolution. The eddy kinetic energy in the deep ocean increased as well, due in part to the greater eastward extent of the Gulf Stream jet, and the fields otherwise compare well with observations (Chassignet and $\mathrm{Xu}$ 2017). Here we examine the vertical structure of the eddies near the Gulf Stream, particularly in the developing meanders.

\section{Results}

\section{a. Linear stability over a slope}

Consider first the stability results with a surface Bickley jet over a flat bottom. These are shown in Figs. 2 and 3. Recall that with $F_{1}=1$, the jet half-width is equal to the deformation radius in the upper layer.

The character of the instability can often be anticipated from the mean PV gradients $q_{i s y}$. A necessary condition for instability is that the $q_{i s y}$ must change sign either within a layer (here, the surface) or between layers (Charney and Stern 1962; Pedlosky 1964). As seen in Fig. 2, $q_{1 s y}$ changes sign in $y$ and also differs in sign with $q_{2 s y}$ along the jet axis. This suggests both baroclinic and lateral instability are possible.

The unstable growth rates are plotted against zonal wavenumber in the upper-left panel of Fig. 3. The curve characteristically increases from zero at $k=0$ to a maximum and then decreases to zero again, at $k=1.7$. The short-wave cutoff is common to the Phillips (1954) and Eady (1949) models. The phase speed, the real part of the eigenvalue $c$ in Eqs. (6) and (7), is shown by the red dashed curve. This increases over much of the wavenumber range, reaching a value near 0.1. For the fastest-growing wave, the speed is near 0.04. This equals the area- and depth-averaged velocity for the mean flow: 


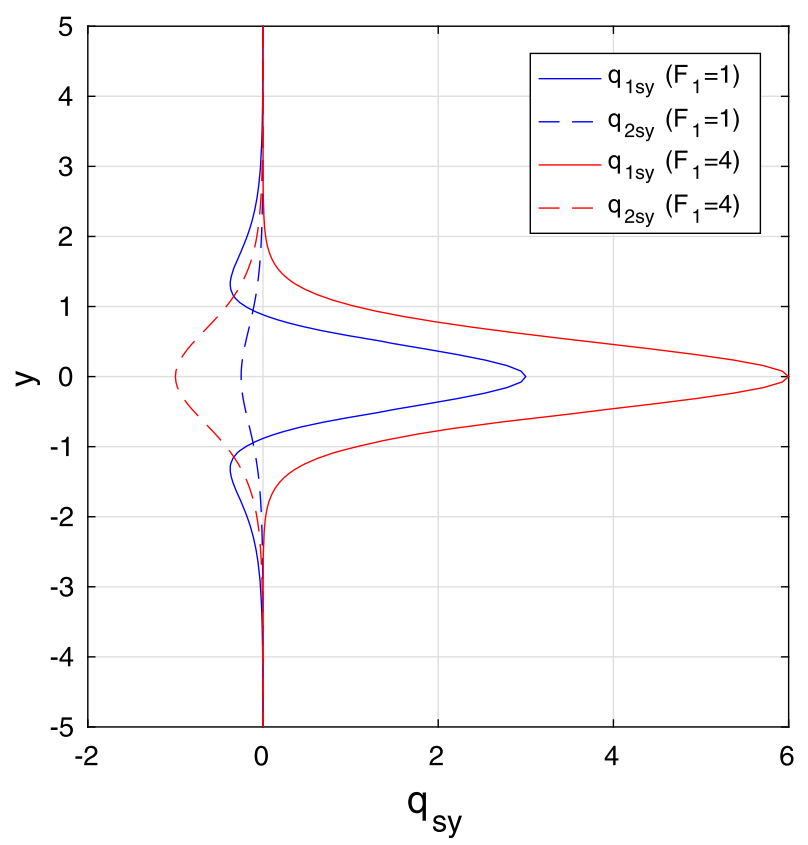

FIG. 2. The layer-wise potential vorticity gradients $q_{i s y}$ for a Bickley jet over a flat bottom. The gradients with $F_{1}=1$ are plotted in blue and those with $F_{1}=4$ in red, while the $q_{1 s y}$ curves are solid and the $q_{2 s y}$ curves are dashed.

$$
\begin{aligned}
\bar{u} & \equiv \frac{1}{2 L_{w}\left(H_{1}+H_{2}\right)} \iint u d z d y \\
& =\frac{H_{1}}{2 L_{w}\left(H_{1}+H_{2}\right)} \int_{-L_{w}}^{L_{w}} U_{o} \operatorname{sech}^{2}(y) d y \approx 0.04 U_{0},
\end{aligned}
$$

which is 0.04 if $U_{0}=1$. A similar equivalence is seen in the Eady and Phillips models.

Shown in the lower-left panel of Fig. 3 are the upperlayer momentum and thickness fluxes, as defined in Eq. (4) (the lower-layer momentum flux is zero with $U_{2}=0$ ). Below $k=0.8$, the momentum and thickness fluxes are comparable and positive, corresponding to growing perturbation energy. At the most unstable wavenumber $(k=0.7)$, the thickness flux exceeds the momentum flux, but only by about $40 \%$. Thus, the fastest-growing wave represents a "mixed" instability, a combination of lateral and baroclinic instability. At wavenumbers exceeding $k=1.2$, however, the thickness flux is weak and the momentum flux dominates, indicating lateral instability. The rapid variations with $k$ are not a numerical artifact but reflect a strong dependence on the eddy scale; consistent results are obtained using more grid points (in $y$ ).

The fastest-growing mode is contoured in the right panels of Fig. 3. The upper-layer eddies are intensified in the middle of the channel, along the jet axis, and are symmetric across the jet. As such, this corresponds to a "sinuous" instability, which would cause the jet to meander (e.g., Flierl et al. 1987; Flierl 1999). The streamlines tilt to the northeast above the jet axis and to the southeast below, consistent with positive/negative momentum fluxes above/below the jet axis and a deceleration of the mean jet (e.g., Flierl et al. 1987; Pedlosky 1987; Vallis 2006).

The deep eddies have larger meridional extent. Their maxima are also shifted downstream relative to those in the upper layer, a characteristic of baroclinic instability (Pedlosky 1987; Lambaerts et al. 2012). The phase shift is consistent with a positive thickness flux, as the deep meridional velocity is positive/negative beneath the positive/negative surface anomalies. Note too that the deep eddies are roughly $25 \%-30 \%$ as strong as those in the upper layer; this is because the lower layer is deeper than the surface.

Shown in Figs. 4 and 5 are the corresponding results with two slopes, one positive and one negative. With $\alpha=-1.6$, the upper-layer PV gradient (upper-left panel of Fig. 4) changes sign across the channel and differs in sign from that in the lower layer, as with a flat bottom. However, with $\alpha=1.6, q_{2 s y}$ is everywhere positive, so that there is no change in the vertical along the jet axis. This suggests baroclinic instability might be suppressed.

The growth rates for both slopes (the blue and red curves in the upper-right panel of Fig. 4) exhibit a maximum at $k=1.1$. But there is a second, larger maximum at $k=1.7$ with the negative slope. Near this latter maximum, the thickness flux greatly exceeds the momentum flux (lower right panel), indicating baroclinic instability. In contrast, the momentum flux is large near the maximum at $k=1.1$ and the thickness flux is nearly zero, with both slopes (lower panels).

For comparison, we calculated the growth rates with a stationary lower layer, that is, with a one-and-a-halflayer version of the model. The result (the black curve in the upper-right panel of Fig. 4) closely resembles the other two curves at small wavenumbers, and the positive slope curve (in blue) over the entire range of $k$. This is consistent with the lower layer being effectively inactive in these instances.

The most unstable waves are shown in Fig. 5. With the negative slope ( $\alpha=-1.6$; Fig. 5, right), the upper-layer perturbations are again centered on the jet axis but have a shorter wavelength than with a flat bottom (Fig. 3). The deep eddies are again shifted downstream, but they are also stronger (roughly $50 \%$ as strong as at the surface) and have strikingly large meridional scales.

With the positive slope ( $\alpha=1.6$; Fig. 5, left), the surface eddies have a larger zonal wavelength. But the deep eddies are 20 times weaker than the surface eddies and, significantly, are aligned with the surface eddies. This 

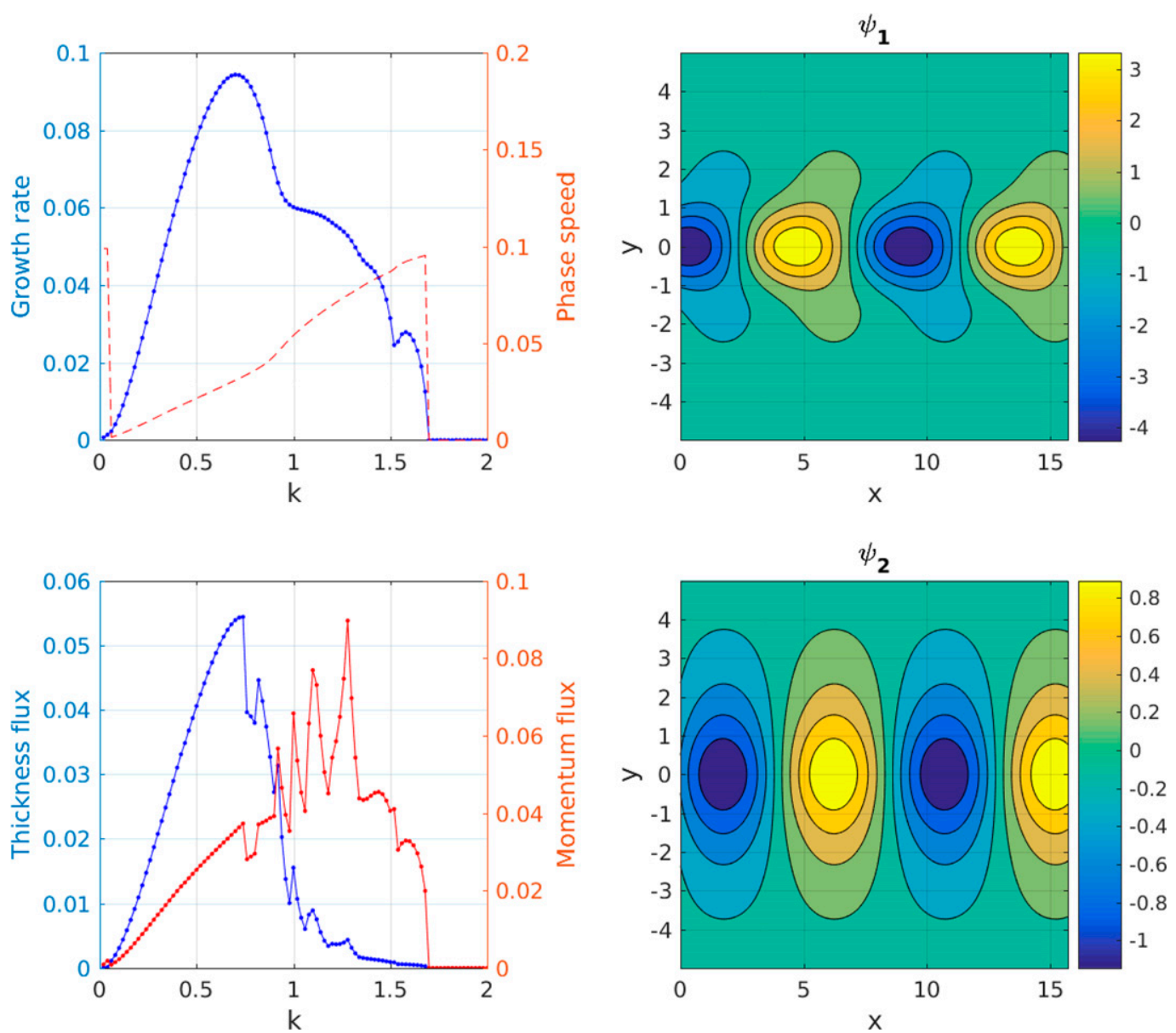

FIG. 3. (top left) The maximum growth rates for the surface Bickley jet with $F_{1}=1$ over a flat bottom, plotted against zonal wavenumber. (bottom left) The energy fluxes are shown, with the thickness flux in blue and the upperlayer momentum flux in red. (right) The layer streamfunctions for the most unstable mode (with $k=0.7$ ) are contoured. Only half of the channel in the $x$ direction is shown, for clarity.

accounts for the weak meridional thickness fluxes, as $v_{2}$ is approximately zero at the maxima of $\psi_{1}$.

The difference between the positive and negative slopes can be understood heuristically in terms of topographic waves, which couple with the surface disturbances under baroclinic instability (e.g., Ribstein and Zeitlin 2013). When the slope is positive (a retrograde jet), the topographic waves propagate opposite to the surface disturbances, which move downstream (Fig. 3). If the slope is steep enough, coupling is prevented and baroclinic instability suppressed. If the slope is negative (a prograde jet), the waves move downstream, which favors coupling. Steeper slopes favor faster waves, so the vertical coupling occurs with smaller waves, which move slower.

The growth rates are plotted over a range of bottom slopes in the upper-left panel of Fig. 6. The central portion of the curve, with its characteristic comma shape, resembles that found for the Eady model with a bottom slope (Fig. 2 of Blumsack and Gierasch 1972). This portion is confined to slopes with $\alpha<0.25$, indicating the associated instability is prevented with larger slopes. One can show that with $\alpha>0.25$ the lowerlayer PV gradient is entirely positive, so that no sign change occurs in the vertical along the jet axis. The central portion of the growth curve persists over negative slopes, with the most unstable wavenumber increasing with slope and the growth rate decreasing. This implies slower-growing, smaller eddies.

However, nonzero growth rates also occur above and below this central portion. The associated growth rates are somewhat smaller, but do not depend on the slope. Thus, the wavenumber of the fastest-growing wave is the same for all slopes with $\alpha>0.25$. Note too that if the negative slope is steep enough (roughly $\alpha<-2.2$ ), the fastest-growing wave is associated with this slopeinvariant portion of the curve. 

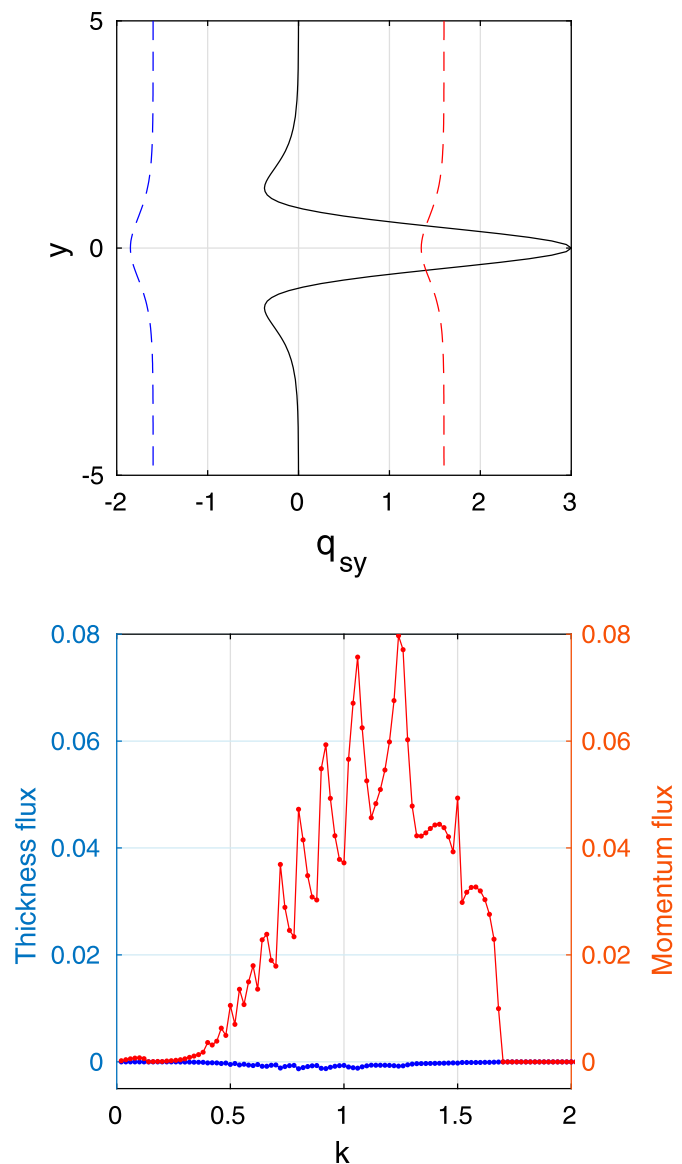
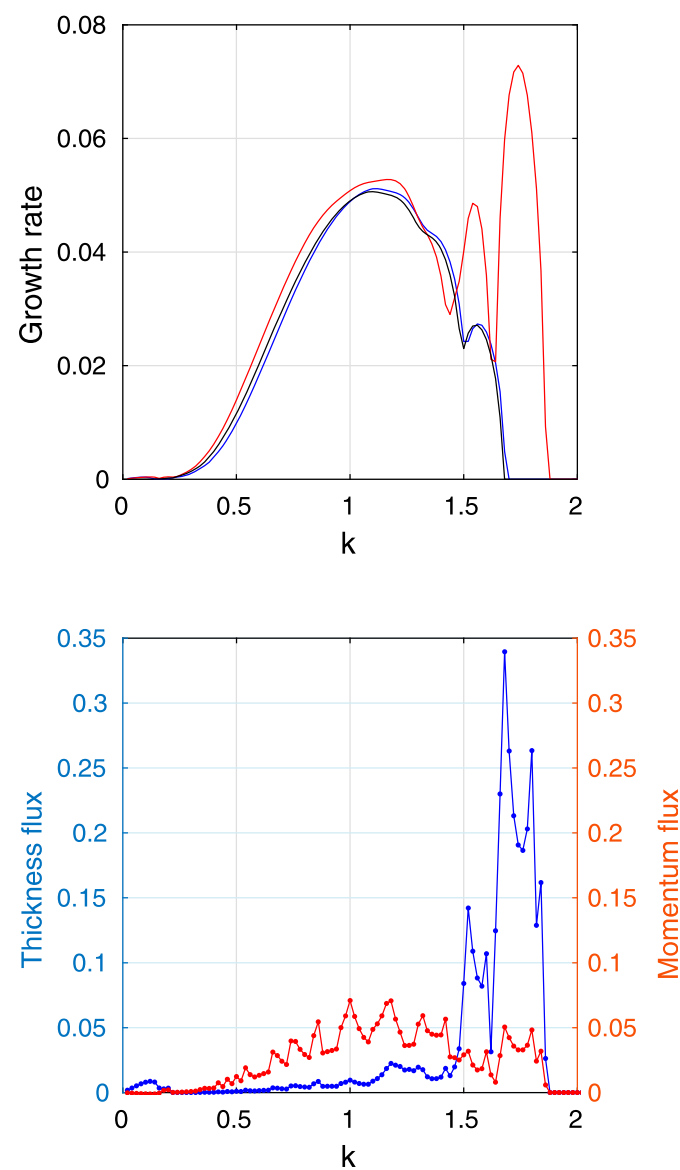

FIG. 4. The Bickley jet with $F_{1}=1$ and two slopes, $\alpha= \pm 1.6$. (top left) The mean PV gradients are $q_{1 s y}$ (black), $q_{2 s y}(\alpha=1.6)$ (red dashed), and $q_{2 s y}(\alpha=-1.6)$ (blue dashed). (top right) The growth rates for $\alpha=1.6$ are in red and for $\alpha=-1.6$ in blue. The growth rates for the equivalent one-and-a-half-layer jet is shown in black, for comparison. The momentum and thickness fluxes are plotted, for (bottom left) $\alpha=1.6$ and (bottom right) $\alpha=-1.6$.

The corresponding thickness fluxes are contoured in the upper-right panel of Fig. 6. These are largest in the central (baroclinic) portion of the growth curve and for wavenumbers exceeding about 1.6. The fluxes increase with wavenumber and are largest for strong negative slopes. In contrast, the fluxes are nearly zero in the regions above and below the central curve. These regions are thus associated with lateral rather than baroclinic instability.

Shown in the lower panels of Fig. 6 are the results for a larger jet, with a half-width twice the deformation radius $\left(F_{1}=4\right)$. The central region is broader and shifted to larger wavenumbers, and has positive thickness fluxes (lowerright panel). The slope-invariant portion, however, is absent, suggesting lateral instability is suppressed. A similar result obtains with a mean flow with no lateral shear at all (the standard Phillips model; not shown).

The change with $F_{1}$ could be anticipated from the mean potential vorticity gradients (Fig. 2 ). With $F_{1}=1$, $q_{1 s y}$ changes sign in $y$, as noted before. But with $F_{1}=4$, the stretching term $F_{1} U_{1}$ overwhelms the curvature term $U_{1 y y}$, so that $q_{1 s y}$ is positive for all $y$. Thus, if the bottom slope is sufficiently large, the PV gradients are positive everywhere, a sufficient condition for stability. Conversely, with a narrower jet, for example, with $F_{1}=0.25$, lateral instability dominates for all slopes (not shown). Then the wavenumber for maximum growth is the same regardless of slope and the upper-layer momentum fluxes dominate.

Suppression of baroclinic instability occurs with $\alpha=O|1|$, which is roughly equivalent to a $1 \%$ grade (section 2a). The topographic grades are at least this large over the continental slope and midocean ridges, but baroclinic instability should still be possible in the interior and over modest negative slopes, that is, those oriented with the shallow water on the right in the Northern Hemisphere. While most of the familiar jets experience positive slopes (e.g., the Gulf Stream, 

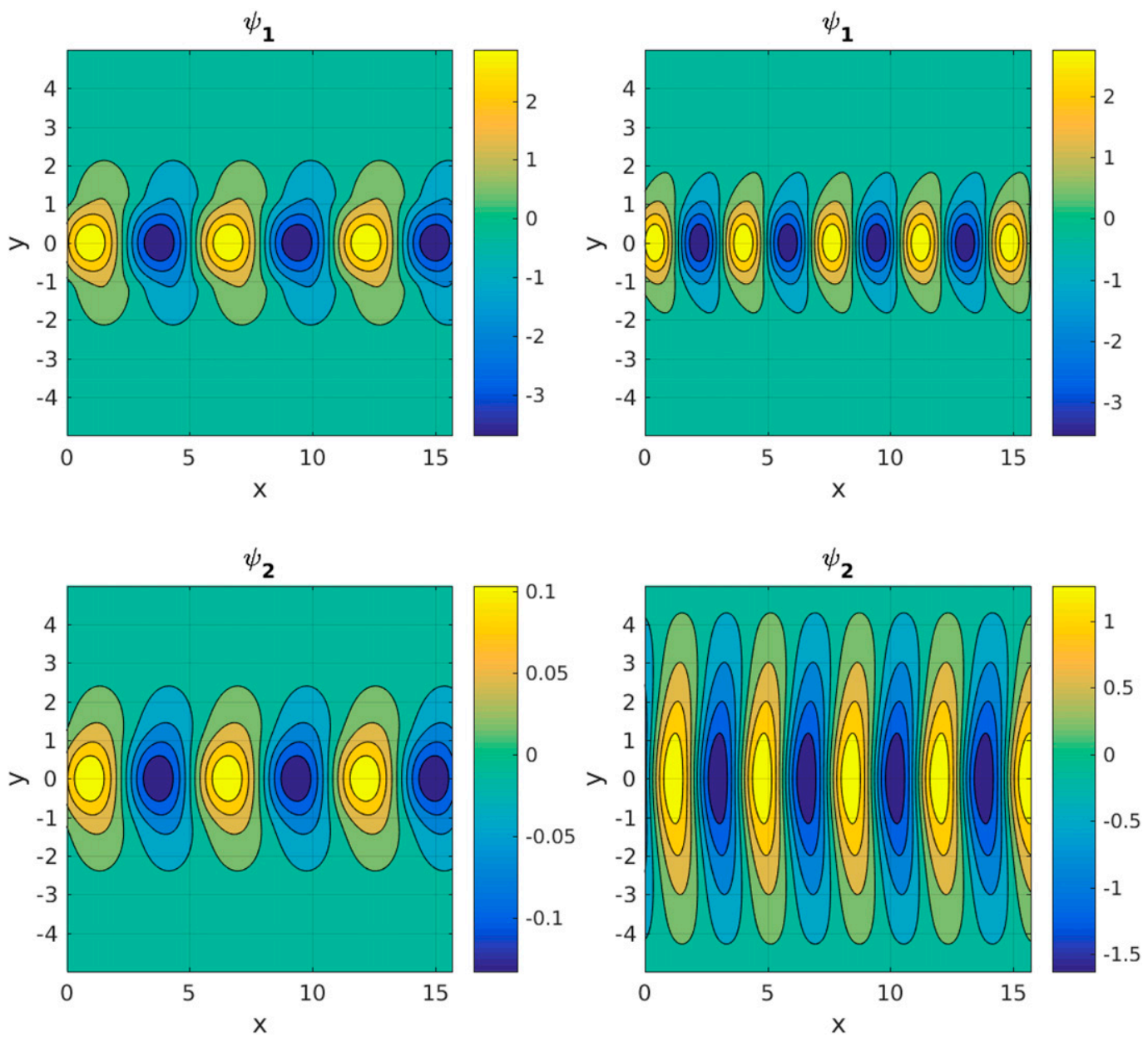

FIG. 5. The most unstable waves for the Bickley jet with $F_{1}=1$ and (left) $\alpha=1.6$ and (right) $\alpha=-1.6$. The (top) $\psi_{1}$ and (bottom) $\psi_{2}$ are shown. Note the difference in color bars in the lower panels.

Kuroshio, and Agulhas), there are notable exceptions (the Norwegian, East Greenland, and Leeuwin Currents). Nevertheless, current meter data suggest that the eddies are significantly surface-intensified in the latter currents too (Woodgate et al. 1999; LaCasce 2005). Foldvik et al. (1988) found that lateral heat transport is weak in the East Greenland Current and concluded that baroclinic instability was not the source of the eddies. Thus, something else may be hindering baroclinic instability.

One possibility is bottom roughness. To test this, we added a ridge to the lower layer, of the form $h=h_{0} \cos (2 \pi y)$. We kept the ridge wavenumber fixed but varied its amplitude $h_{0}$. In line with previous studies without lateral shear (Benilov 2001; Vanneste 2003), identical results were found with larger ridge wavenumbers.

The effect on the growth rates is shown in Fig. 7 for two values of the amplitude. With $h_{0}=1$ (upper panels), the baroclinic portion of the growth curve shifts and the growth rates are somewhat reduced. With $h_{0}=2$ (lower panels), the baroclinic portion shifts further toward larger, positive slopes. As such, unstable growth is dominated by the slope-invariant (lateral instability) portion over the range of slopes shown.

Why does the baroclinic portion shift toward positive slopes? This can also be understood in terms of topographic waves. Without a large-scale slope, the sinusoidal ridge supports both eastward and westward propagating waves, with the same phase speeds. Adding a negative slope steepens the ridge slopes on the north sides, increasing westward phase propagation which hinders coupling with surface disturbances. But adding a positive slope steepens the ridge slopes on the south sides, favoring eastward propagation and vertical coupling. The higher the ridge, the faster the ridge-trapped waves propagate. Thus, a larger positive slope is required to reduce the westward propagation. 

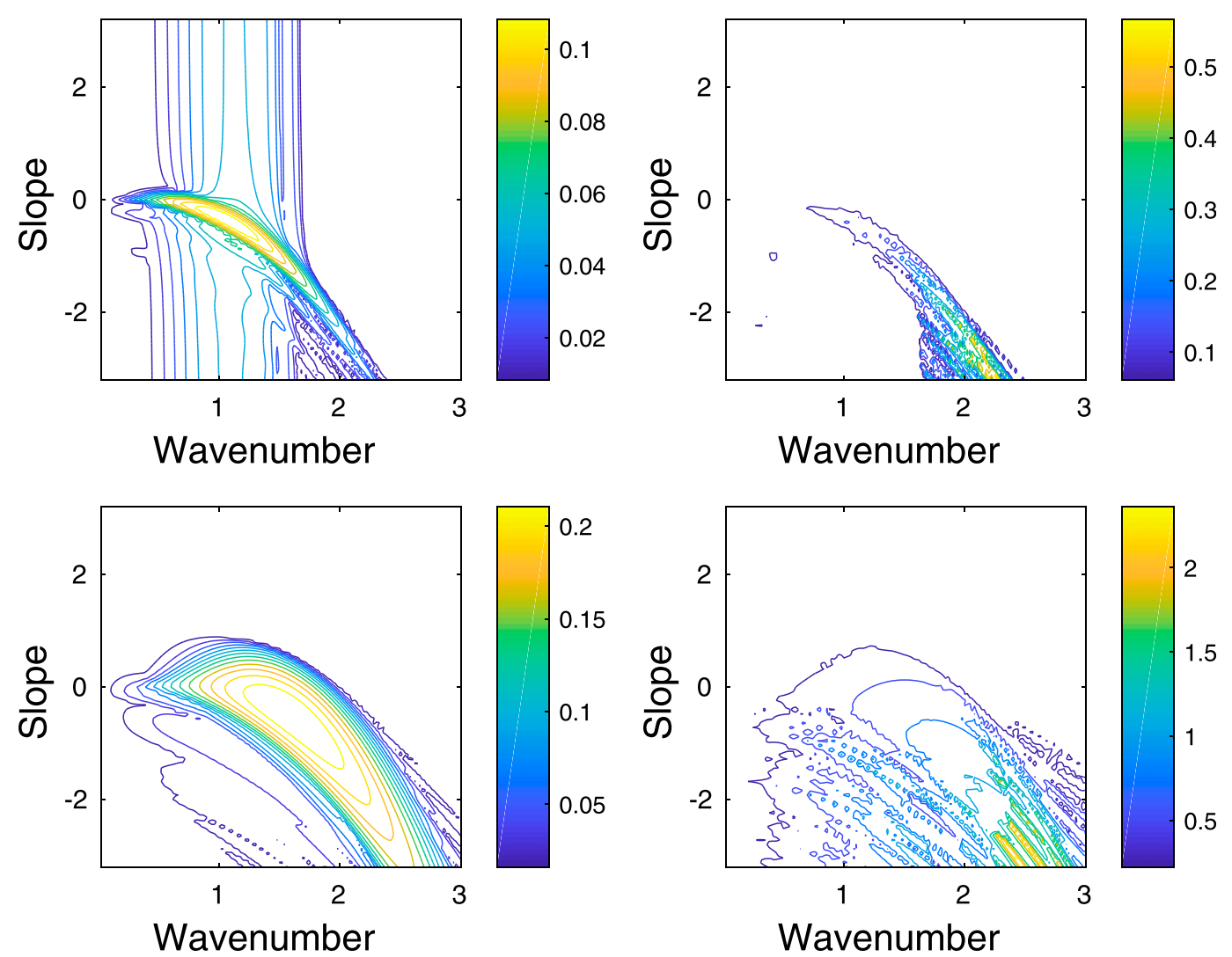

FIG. 6. (top left) The maximum growth rate for the Bickley jet with $F_{1}=1$ as a function of zonal wavenumber and bottom slope and (top right) the meridional thickness transport. (bottom) Comparable results for the Bickley jet with $F_{1}=4$ are shown.

The most unstable wave with the larger ridge $\left(h_{0}=2\right)$ and a slope of $\alpha=-1.6$ is shown in Fig. 8 . Recall that without the ridge, the deep eddies were half as strong as the surface eddies and shifted downstream (Fig. 5). With the ridge, the deep eddies are much weaker and have smaller meridional scales, mirroring the ridge itself. Moreover, the deep eddies are anti-aligned with those at the surface, lying beneath the latter but having the opposite sign. Identical deep eddies obtain with $\alpha=1.6$, and indeed with no slope at all.

Significantly, the deep eddies are always present, even when instability is confined to the surface layer. How does the lower layer spin up, if baroclinic instability is suppressed? Consider the lower-layer $\mathrm{PV}$ equation for the perturbation, that is, Eq. (7) with $U_{2}=0$ :

$$
q_{2 s y} \hat{\psi}_{2}=c F_{2} \hat{\psi}_{1}+c\left(\frac{\partial^{2}}{\partial y^{2}}-k^{2}-F_{2}\right) \hat{\psi}_{2}
$$

If the topography is steep, $q_{2 s y}$ is dominated by the largescale slope, the ridge gradient, or both:

$$
q_{2 s y} \approx \alpha+\frac{\partial}{\partial y} h .
$$

If the deep flow is weak, the third and fourth terms on the RHS of Eq. (10) can be neglected. The second term $\left[c\left(\partial^{2} / \partial y^{2}\right) \hat{\psi}_{2}\right]$ need not be small, however, as the ridge has a small meridional scale. Under these conditions, Eq. (10) is approximately

$$
\frac{\partial^{2}}{\partial y^{2}} \hat{\psi}_{2}-\frac{\alpha+\frac{\partial}{\partial y} h}{c} \hat{\psi}_{2} \approx-F_{2} \hat{\psi}_{1} .
$$

Physically, this implies that the lower-layer eddies are forced by upper-layer eddies via interfacial stretching, which generates both cross-isobath flow and relative vorticity.

Solutions to Eq. (11) were obtained numerically, and some examples are shown in Fig. 9. With a bottom slope of $\alpha=1.6$ and no ridges (left panel), the predicted streamfunction has the same structure and amplitude as for the full $\psi_{2}$ (lower-left panel of Fig. 5). In this case, the second (cross-isobath flow) term dominates in Eq. (11), 

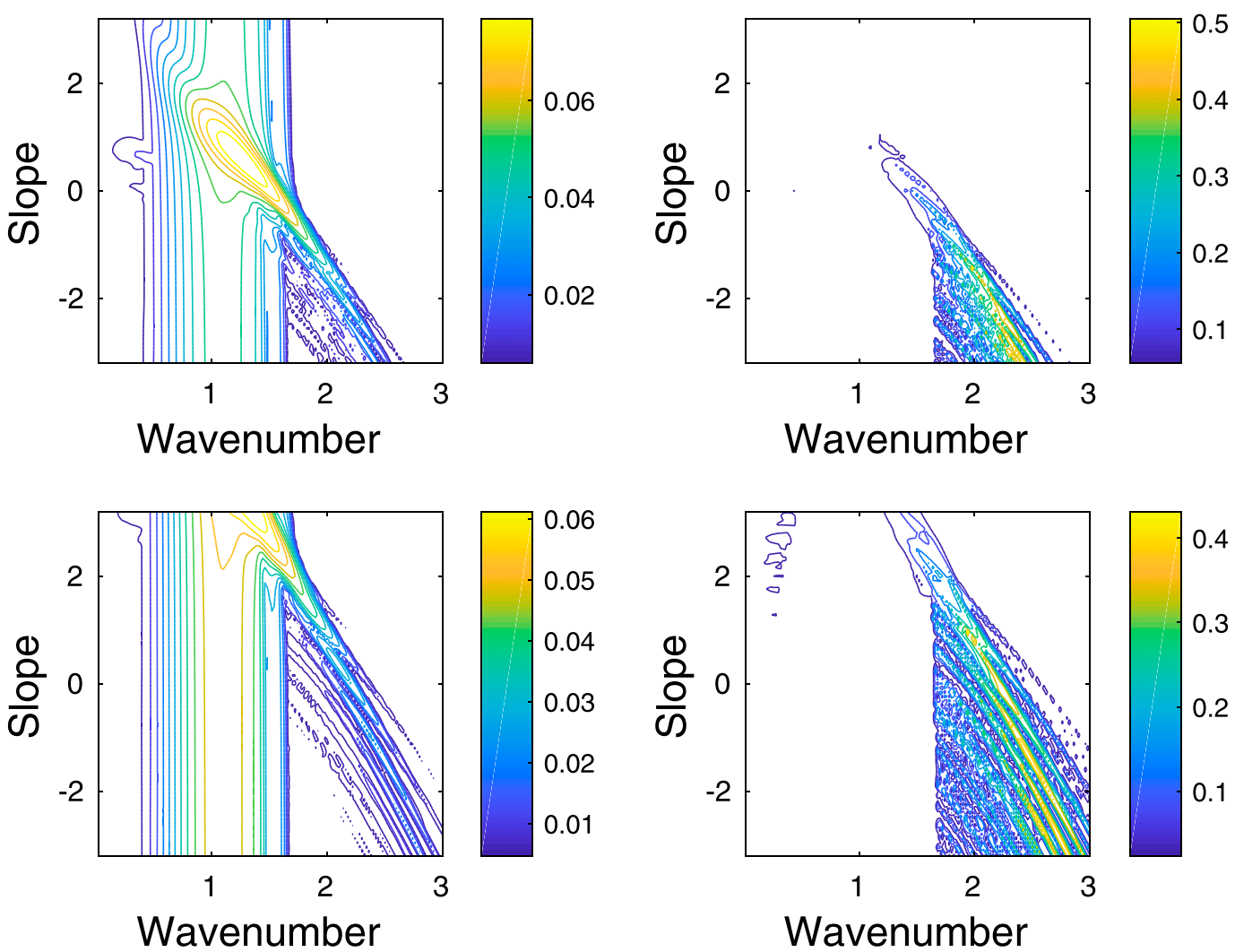

FIG. 7. The (left) growth rates and (right) thickness fluxes as functions of the zonal wavenumber and bottom slope, with $F_{1}=1$ and submarine ridges. The topographic amplitude is (top) $h_{0}=1$ and (bottom) $h_{0}=2$.

and a similar result is obtained by neglecting the first (relative vorticity) term. This explains why the deep eddies have the same sign as the surface eddies.

In the right panel of Fig. 9 is the result with the steeper ridge, with $h_{0}=2$. This also closely resembles the full $\hat{\psi}_{2}$ (lower panel of Fig. 8). The anticorrelation with the surface eddies, noted earlier, is the result of the deep response being dominated by the relative vorticity term in Eq. (11). Significantly, the streamfunction in Fig. 5 was obtained with no bottom slope, while that in Fig. 8 had a large-scale slope of $\alpha=-1.6$. Thus, the slope contribution here is greatly outweighed by that of the ridge.

Thus, when the topography is sufficiently strong, the deep flow is weak and forced by interfacial motion associated with the surface eddies - a very different situation than with baroclinic instability. In such cases, the magnitude of the deep flow depends on the stratification, the strength of the surface flow and the severity of the topographic slopes.

What determines the eddy scale when lateral instability dominates? To see, we calculated solutions with the one-and-a-half-layer version of the model, using various jet widths and two values of $F_{1}$. As noted, the jet is unstable only if $q_{1 s y}$ changes sign, which requires that the half-width be less than twice the deformation radius.
As seen in Fig. 10, the most unstable wavelength scales linearly with jet width. ${ }^{1}$ A least squares fit in Fig. 10 yields a proportionality factor of 5.1. Thus a jet with a half-width of $40 \mathrm{~km}$, like the Gulf Stream, would have a meander wavelength of about $200 \mathrm{~km}$.

If the jet width is too large, the most unstable wavelength increases faster than linearly. At the same time the growth rates decrease toward zero (not shown). In such cases, the instability is affected by the channel walls. Using a jet width that is one-fifth the channel width, as in the previous examples, was sufficient to avoid this, as noted in section 2 .

\section{b. Observations of roughness}

Baroclinic instability is suppressed with a nondimensional topographic amplitude, $h_{0}=O|1|$. To assess how large this is, consider the nondimensional height:

$$
h=\frac{h_{\mathrm{dim}}}{\operatorname{Ro} H_{2}}\left(\frac{L_{w}}{L_{t}}\right),
$$

\footnotetext{
${ }^{1}$ Such a linear dependence is also seen in piecewise linear models of barotropic instability (Vallis 2006; Cushman-Roisin and Beckers 2011).
} 

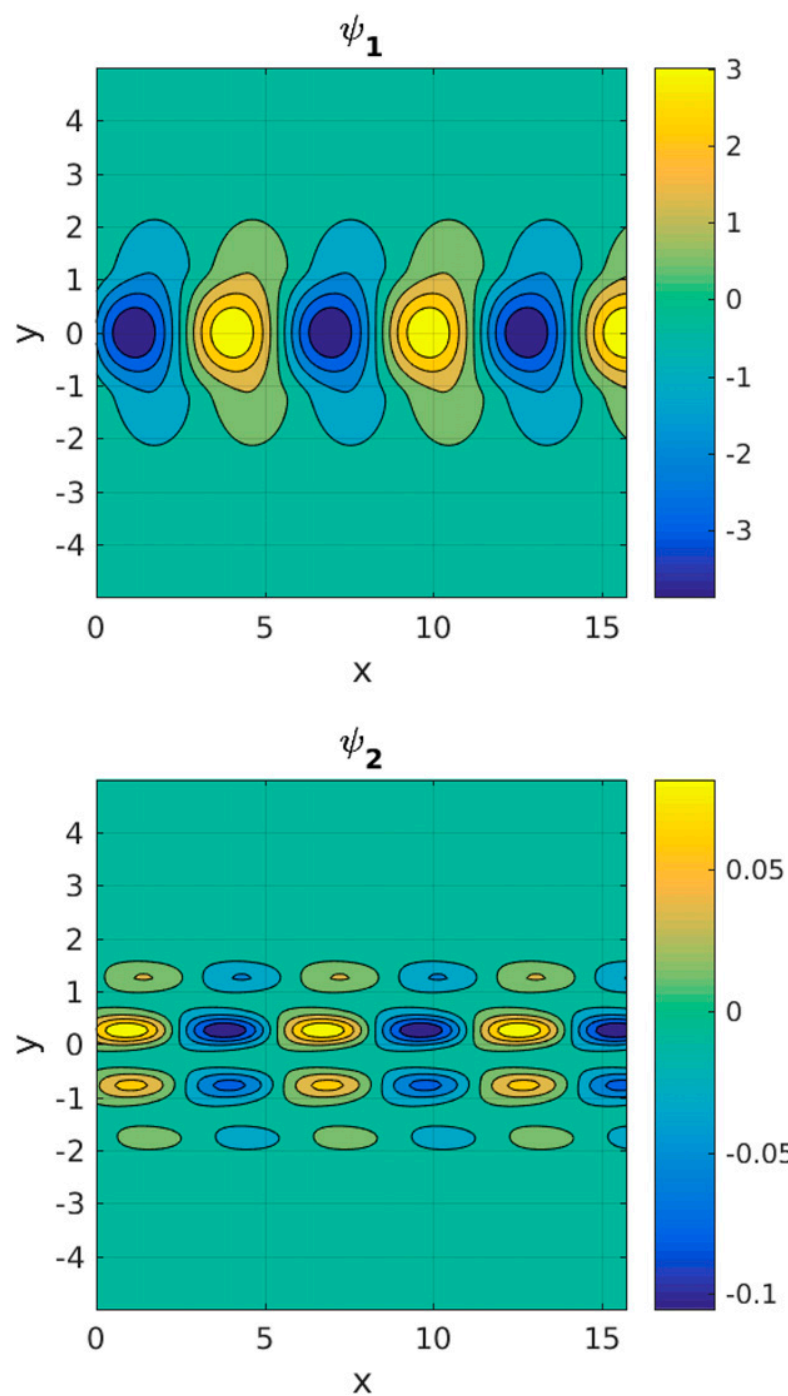

FIG. 8. The most unstable wave with the ridge with $h_{0}=2$ and a large-scale slope, $\alpha=-1.6$. The (top) upper- and (bottom) lowerlayer streamfunctions are shown.

which follows from scaling the topographic term in Eq. (2). Note we differentiate the ridge $L_{t}$ and jet $L_{w}$ scales, as the former is assumed much smaller than the latter. Assuming Ro $=0.1, H_{2}=4000 \mathrm{~m}$, and $L_{t}=1 \mathrm{~km}$, an order-one topographic term implies a dimensional height of approximately $10 \mathrm{~m}$. The choice of ridge scale is somewhat arbitrary, but small compared to the jet width of $50 \mathrm{~km}$. Note with such a height, the topographic grade is roughly $1 \%$, comparable to the value required to suppress baroclinic instability over a (positive) linear slope.

Are such topographic heights realistic? To find out, we examined seafloor roughness measurements in locations beneath the Gulf Stream, Kuroshio, and the ACC, as described in section $2 \mathrm{~b}$. The sites and their associated RMS values are shown in the map in Fig. 11. The RMS heights are also listed in Table 1, for 1- and $10-\mathrm{km}$ scales, as are the other parameters for the sampled sites (location, area, bathymetric coverage, depth, etc.). The sites are plotted in Fig. 11, with the color indicating the RMS topographic height in each. The largest heights are found in the Southern Ocean and beneath the Kuroshio and somewhat smaller values below the Gulf Stream.

The RMS height is plotted against longitude for the three currents in Fig. 12. On the left are the values for $1-\mathrm{km}$ search diameters with $10-\mathrm{km}$ values on the right. The Gulf Stream region has the lowest roughness, with RMS values typically less than $10 \mathrm{~m}$ on the $1-\mathrm{km}$ scale and $40 \mathrm{~m}$ on the $10-\mathrm{km}$ scale. The current lies over the passive continental margin, the continental slope, and the heavily sedimented old North Atlantic Ocean basin, and these regions are relatively smooth, except for the margin slope and some seamount chains.

The roughness is considerably greater beneath the ACC. The bathymetry includes that from young seafloor formed along slow-spreading ridges, such as the Southwest Indian Ridge, where extensive faulting generates prominent topography (scarps with scales exceeding $1 \mathrm{~km}$ ) and limited sediment cover (that would reduce the roughness). Along the current's path, the maximum RMS values are typically above $100 \mathrm{~m}$ for the $10-\mathrm{km}$ search radius and $20 \mathrm{~m}$ for $1-\mathrm{km}$ radius (Fig. 12). In fact the roughness here is highly anisotropic, with its orientation largely controlled by faults that develop parallel to the ridge axis. The faults are responsible for the formation of the abyssal hills that are pervasive throughout the ocean floor (Menard and Mammerickx 1967; Macdonald et al. 1996; Olive et al. 2015; and references therein). Thus, for example, the ridge axis is nearly parallel to the ACC between Africa and Antarctica and nearly perpendicular at the crossing of the east Pacific Rise in the Southern Pacific (Fig. 11). As noted, this could well impact jet stability (Benilov 2001).

The roughness beneath the Kuroshio is intermediate between that found below the Gulf Stream and the ACC. The RMS values are from 10 to $30 \mathrm{~m}$ at the $1-\mathrm{km}$ scale and from 80 to $200 \mathrm{~m}$ at the $10-\mathrm{km}$ scale. Off Japan, the highly deformed accretionary wedge associated with the subduction of the Pacific plate, together with pervasive volcanic edifices, results in a greater roughness than on the sedimented seafloor of the eastern North American margin.

Thus, in all three regions, the topographic heights may be sufficient to inhibit baroclinic instability. Of course, the preceding stability results apply to one-dimensional ridges, not fully two-dimensional topography like that described here, but work in progress suggests that $2 \mathrm{D}$ 

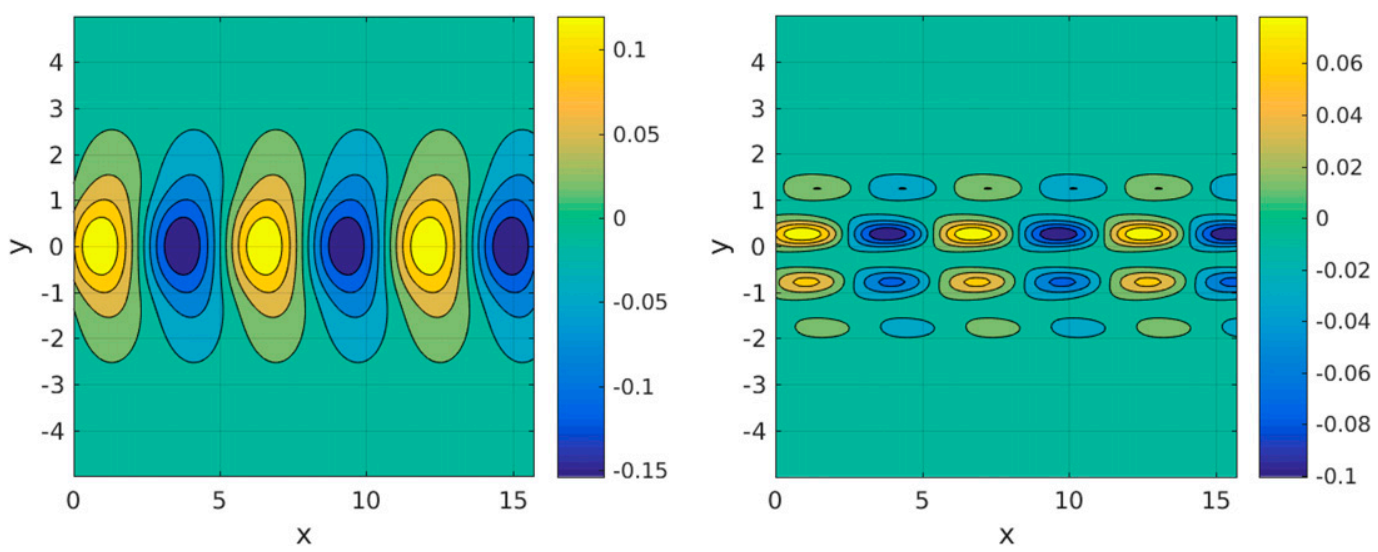

FIG. 9. (left) The solution for $\psi_{2}$ with the approximate balance given in Eq. (11), with a large-scale slope $\alpha=1.6$ (to be compared to Fig. 5, bottom left) and (right) with a ridge with $h_{0}=2$ (to be compared to Fig. 8, bottom).

topography inhibits baroclinic instability similarly. If so, the unstable eddies associated with the great boundary currents should be vertically aligned, with relatively weak bottom flows. To test this, we turn to a fullcomplexity model of the Gulf Stream.

\section{c. Gulf Stream eddies in HYCOM}

Observational surveys of eddies below the Gulf Stream have been made previously. Strong, intermittent velocities, with speeds exceeding $10 \mathrm{~cm} \mathrm{~s}^{-1}$, are frequently observed (Luyten 1977; Richardson et al. 1981; Welsh et al. 1991). These are 5-10 times weaker than the

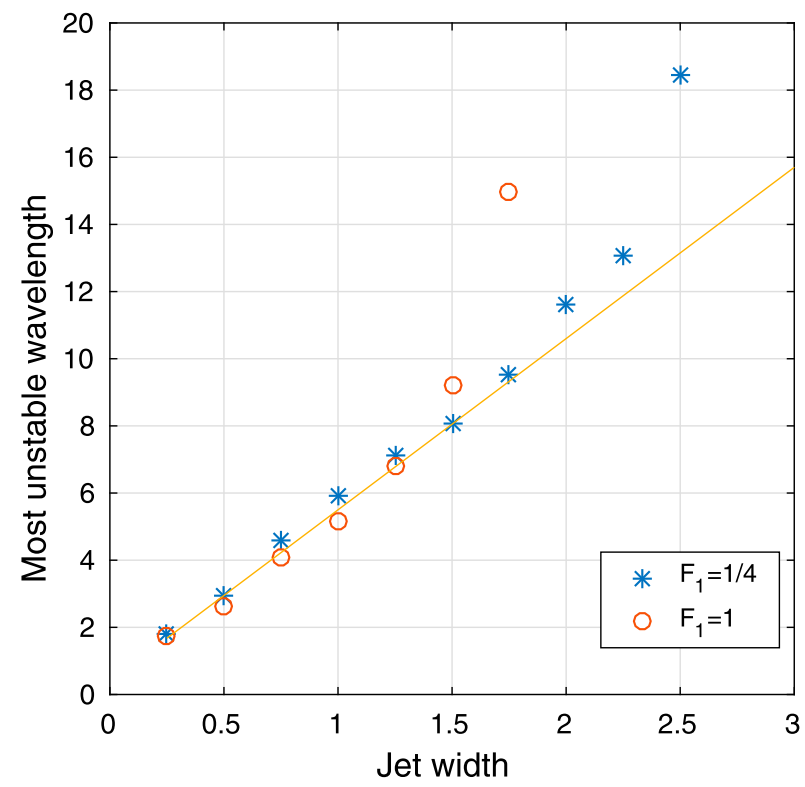

FIG. 10. The most unstable wavelength as a function of jet width, with no motion in the lower layer and with $F_{1}=1$ (circles) and $F_{1}=1 / 4$ (asterisks). The linear (least squares) fit has $\lambda_{\max }=5.1 \mathrm{~L}$. Recall that the channel extends from $y=-5$ to $y=5$. surface eddy speeds (Richardson 1983; Schmitz 1984; Bower and Hogg 1996). The deep eddies have been associated with topographic waves on the continental rise (Thompson and Luyten 1976; Hogg 1981; Pickart 1995) and with deep cyclones forming under meander troughs (Johns et al. 1995; Bower and Hogg 1996; Savidge and Bane 1999a; Andres et al. 2016). The extent to which the eddies are generated by lateral or baroclinic instability has been debated, as discussed hereafter.

Here we examine the vertical structure of eddies in the $1 / 50^{\circ} \mathrm{HYCOM}$ simulation described in section $2 \mathrm{c}$. As noted, this particular simulation exhibits remarkably realistic structure in the Gulf Stream region, making it a good test bed for studying eddy structure.

The model's surface vorticity in the western North Atlantic on a day in late winter (1 March) is shown in Fig. 13a. The Gulf Stream separates from the coast, with cyclonic vorticity on its northern flank and anticyclonic vorticity on the southern. The meanders are clearly evident downstream of Cape Hatteras, as is a series of warm (anticyclonic) and cold (cyclonic) core rings. The eddy field shows startling complexity, including energetic submesoscale features (Chassignet and Xu 2017).

The black contour along the jet axis represents the five-year mean position of the 20 -cm sea surface height (SSH) contour. This is a good proxy for the maximum gradient of SSH, and we use it to indicate the time-mean axis of the stream. Shown in the lower two panels are the relative vorticity (Fig. 13b) and the meridional velocity (Fig. 13c) along this contour. These clearly reveal the vertical structure of the meander eddies.

The eddies' vorticity is strongly surface intensified, being largely restricted to the upper $1000 \mathrm{~m}$. The deep vorticity anomalies, which extend to the bottom, are much weaker and are mostly aligned with the surface features. There are structures that are bottom-intensified and not 


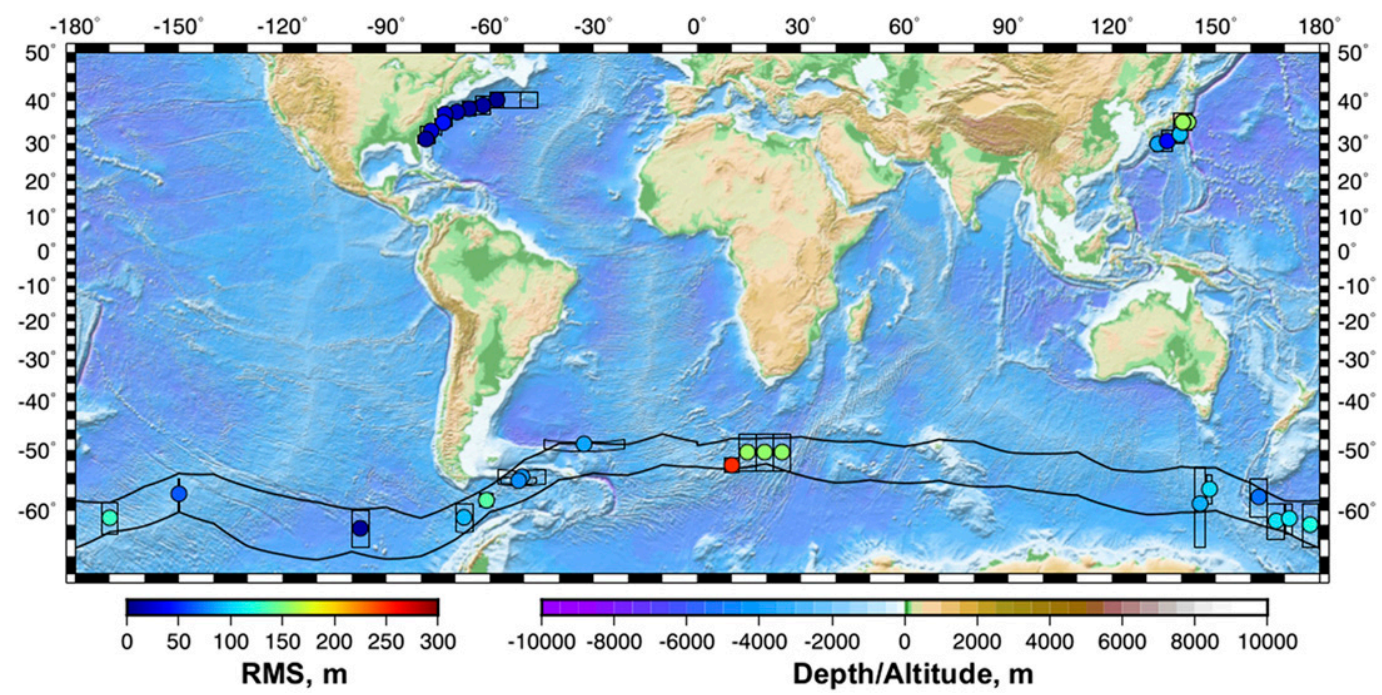

FIG. 11. A map of RMS topographic height in selected regions, near the Gulf Stream, Kuroshio, and the ACC.

obviously linked to surface eddies; the most prominent of these are anticyclones that are trapped over seamounts and weaker features over the continental margin (possibly topographic waves). But the most common structures are the deep expressions of the surface eddies, lying directly below.

The meridional velocities (Fig. 13c) yield a similar impression of surface-intensified eddies, though the field decays more slowly with depth. Nevertheless, the impression of deep flow that is mostly aligned in the vertical is the same. There are instances of apparent tilting, but the tilt direction is not consistently downstream or upstream. This contrasts strongly with the core of the Gulf Stream itself, which tilts to the north moving toward the surface [as seen in observations (Richardson 1985; Johns et al. 1995; Bower and Hogg 1996) and also in the present simulation (Chassignet and $\mathrm{Xu}$ 2017)].

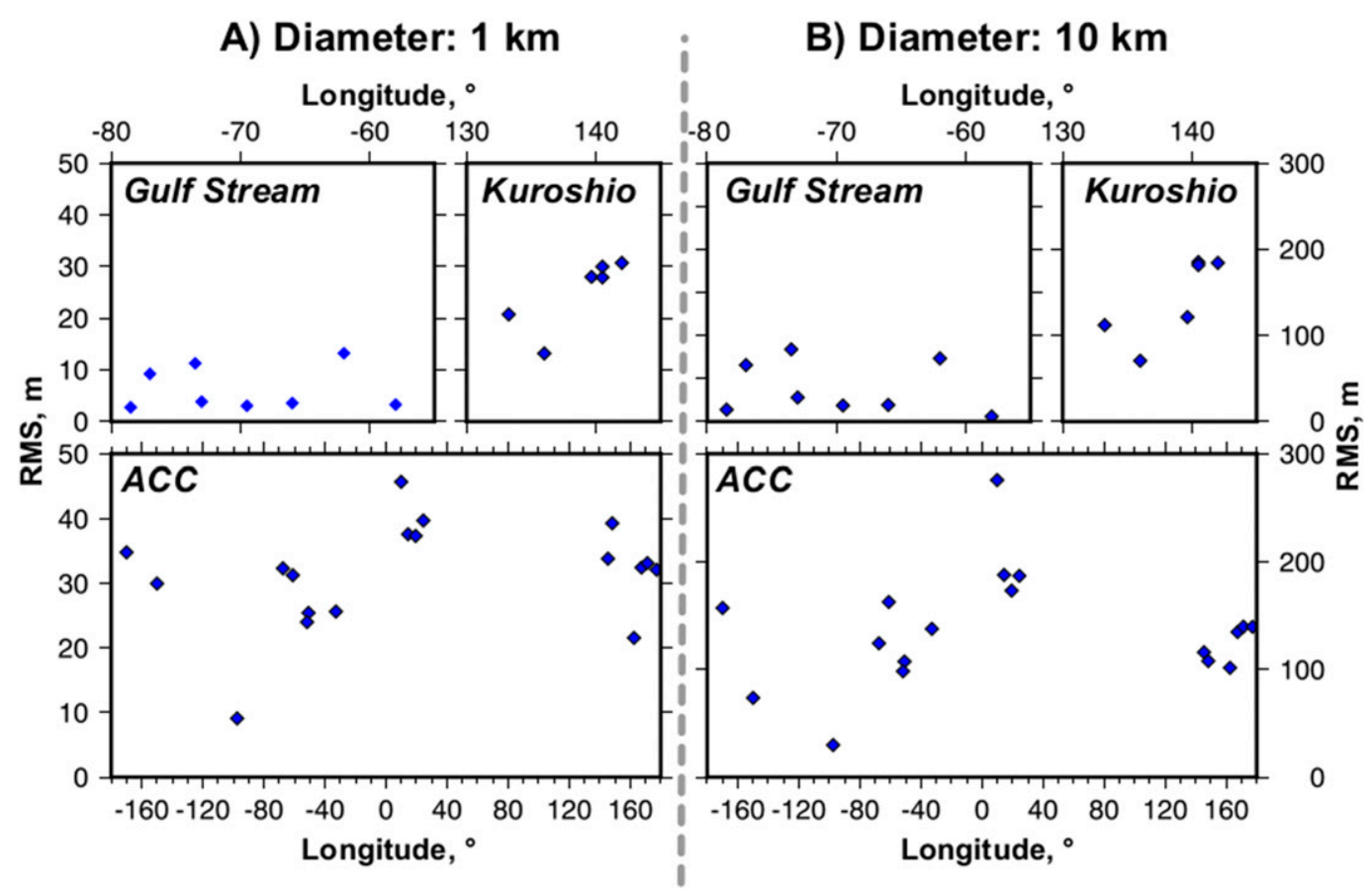

FIG. 12. The RMS topographic heights in the three regions shown in Fig. 11. The heights are averaged over circular regions with (a) 1- and (b) 10-km diameter. 


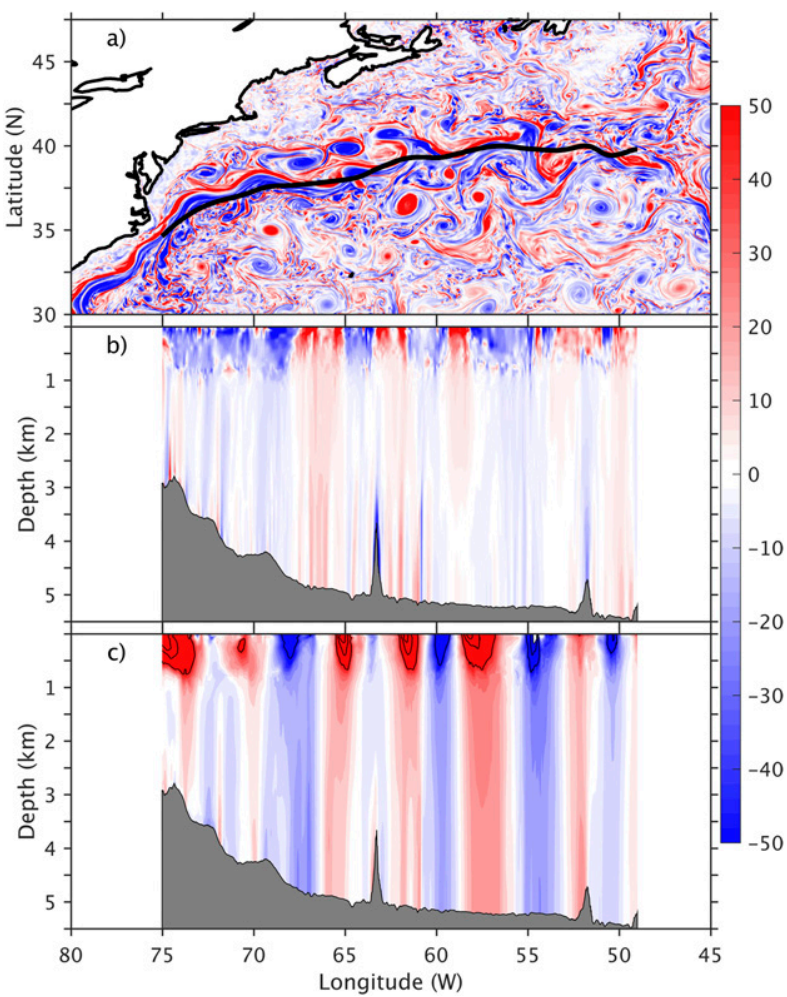

FIG. 13. (a) The surface vorticity (color shaded; in increments of $10^{-6} \mathrm{~s}^{-1}$ ) in the Gulf Stream region from the HYCOM simulation, based on daily means for 1 Mar. The thick black line denotes the 5 -yr mean of the 20-cm SSH contour, as a proxy for the time-mean Gulf Stream axis at the surface. Vertical distributions of (b) relative vorticity (in increments of $10^{-6} \mathrm{~s}^{-1}$ ) and (c) the meridional velocity $\left(\mathrm{cm} \mathrm{s}^{-1}\right)$ along the mean axis at the same time. The black contours in (c) denote velocities of 50,100, and $150 \mathrm{~cm} \mathrm{~s}^{-1}$.

Shown in Fig. 14 is the relative vorticity at $2000 \mathrm{~m}$. The black contours are the SSH contours, which help orient the deep eddies with the surface structures. Deep cyclones (in red) are prominent and these fill the regions beneath meander troughs. Instead of being discrete cyclonic vortices, the features are better characterized as cyclonic regions, mirroring the surface meanders. Regions of anticyclonic vorticity are also observed, beneath the crests, but these are more fragmented and less evident further downstream. Thus, downstream development favors deep cyclones over anticyclones in the meanders. Note too that the deep vorticity below the cold core ring centered near $62^{\circ} \mathrm{W}$ is mostly aligned with the surface eddy.

A horizontal section of the vorticity at $4000 \mathrm{~m}$ (not shown) also shows cyclones lying directly beneath the meanders. In addition, one observes small-scale eddies that have no expression at the shallower levels; these appear on both flanks of the Gulf Stream and well into the interior. Their bottom intensification is suggestive of topographic waves, but their origin remains to be elucidated.

The fields from a day in late summer (1 September) are shown in Fig. 15. The surface vorticity (Fig. 15a) is much smoother than in winter, as the mixed layer is shallower and the submesoscales are less active (e.g., Callies et al. 2015; Chassignet and Xu 2017). There is also a more prominent bottom-intensified, topographic wavelike feature over the continental margin. But besides these, the large-scale structure is very similar. The eddies along the mean SSH contour have relative vorticity that is intensified in the upper $1000 \mathrm{~m}$, while the deep vorticity is weaker and vertically aligned. The meridional velocity likewise suggests surface intensification and vertical alignment.

The linear stability analysis is more applicable to the developing eddies in the meanders than to the detached rings, but the latter exhibit a similar structure. Shown in Fig. 16 are fields from the cold core ring centered near $36.5^{\circ} \mathrm{N}, 57.5^{\circ} \mathrm{W}$ in Fig. 15 . The fields have been averaged following the ring, during the period from 1 August to 31 September. The surface vorticity is confined to a circular region roughly $100 \mathrm{~km}$ in diameter (Fig. 16a). The deep vorticity is weak (Fig. 16b), but the velocity arrows suggest the center is shifted slightly to the south of the surface center. A north-south section of the vorticity (Fig. 16d) supports a slight meridional tilt, while the east-west section (Fig. 16c) indicates no tilt at all. And the horizontal velocities, which span a region greater than $200 \mathrm{~km}$, exhibit little vertical tilt. Thus, the eddy has much the same structure as those in the meander, being surface intensified and at most weakly tilted in the vertical.

Thus, the vortices comprising the Gulf Stream meanders are intensified in the upper $1000 \mathrm{~m}$ and are largely vertically aligned below. The same structure is seen with the rings that have pinched off from the stream. Both cyclonic and anticyclonic regions appear, though the cyclones are more pronounced at depth and downstream from Cape Hatteras. This structure is in contrast to the cases in section 3a with baroclinic instability, in which the deep eddies had broad crossstream extent and were vertically shifted downstream. But the configuration resembles that in the strong topography cases, where the deep eddies mirrored those at the surface.

Some aspects suggest that finite Rossby number effects may be important. The deep cyclones (Fig. 14) are about $1 / 5$ as strong as at the surface, which is somewhat greater than in the QG solutions. Also, the asymmetry between deep cyclones and anticyclones suggests their response to the divergence imposed by interfacial motion differs, perhaps because cyclones 


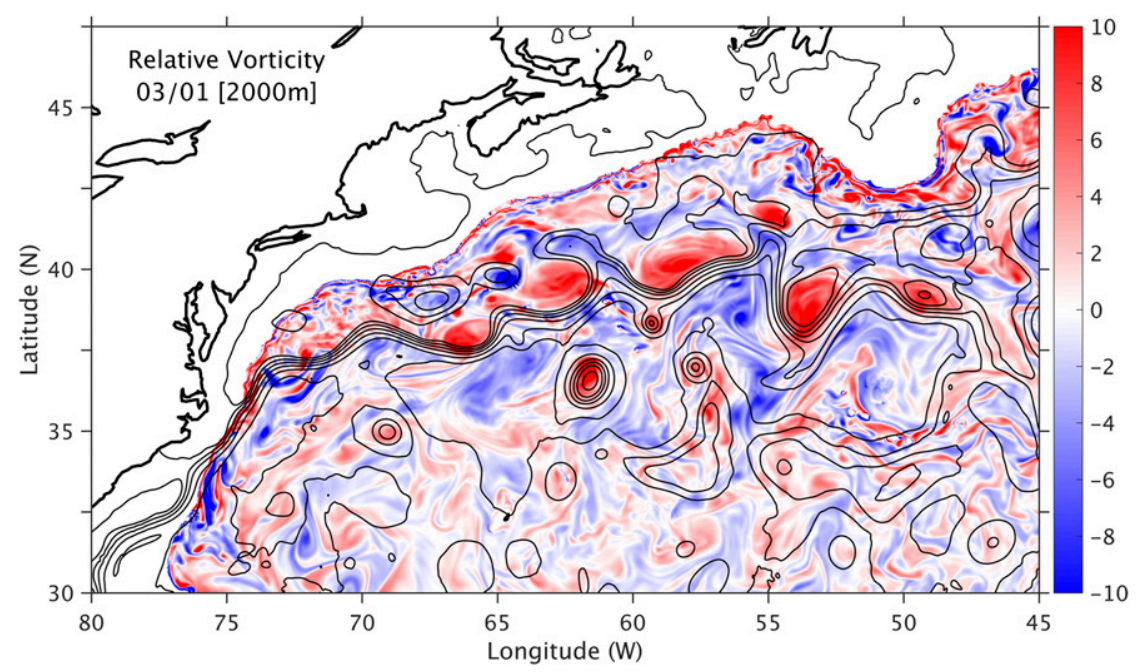

FIG. 14. The relative vorticity at $2000 \mathrm{~m}$ on 1 Mar. The vorticity is contoured in increments of $10^{-6} \mathrm{~s}^{-1}$. The black contours indicate the SSH contours on the same day.

are more intense under the gradient wind balance (e.g., Holton 2004). Consistently, cyclonic (anticyclonic) eddies in this simulation are $20 \mathrm{~cm} \mathrm{~s}^{-1}$ stronger (weaker) than the equivalent geostrophic eddies (Chassignet and Xu 2017).

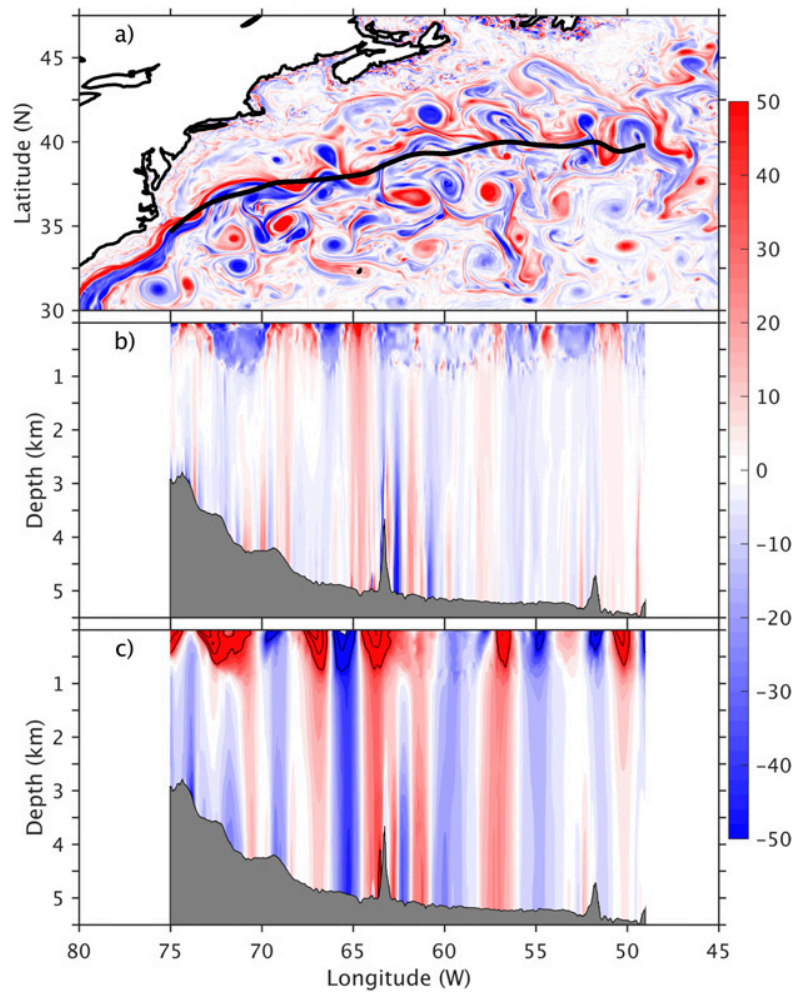

FIG. 15. As in Fig. 13, but based on daily mean fields in summer (1 Sep).

\section{Summary and discussion}

A sufficiently strong bottom slope and/or bottom roughness can hinder baroclinic instability of a surface current. This favors lateral (barotropic) instability at the surface, if the current is narrower than roughly four deformation radii. The resulting eddies produce meanders with a wavelength approximately 5 times the jet half-width. The deep eddies, forced by the surface eddies via interfacial displacement, are aligned with the surface eddies and are significantly weaker.

A large-scale bottom slope with roughly a $1 \%$ grade is sufficient to suppress baroclinic instability for a retrograde jet like the Gulf Stream. Prograde jets require steeper slopes, although lateral instability will still dominate if the current is narrow enough. Such topographic grades are found over the continental slope and midocean ridges but are less common in the interior. The large-scale slope beneath the Gulf Stream extension would not be sufficient to prevent baroclinic instability.

However, a $1 \%$ grade can also be achieved with bottom roughness; as the lateral scales are small, the slopes can be large even if the topographic amplitudes are modest. The results suggest $10-\mathrm{m}$ bumps with a wavelength of $1 \mathrm{~km}$ are sufficient to hinder baroclinic instability. Shipboard multibeam echo-sounding data show that such topographic heights are common beneath the Kuroshio, the ACC, and (to a lesser extent) the Gulf Stream. Consistent with this, the eddies that comprise Gulf Stream meanders in a high-resolution HYCOM simulation are significantly surface-intensified and vertically aligned. Thus, bottom roughness may indeed affect ring formation in regions like the Gulf Stream and Agulhas extensions. 

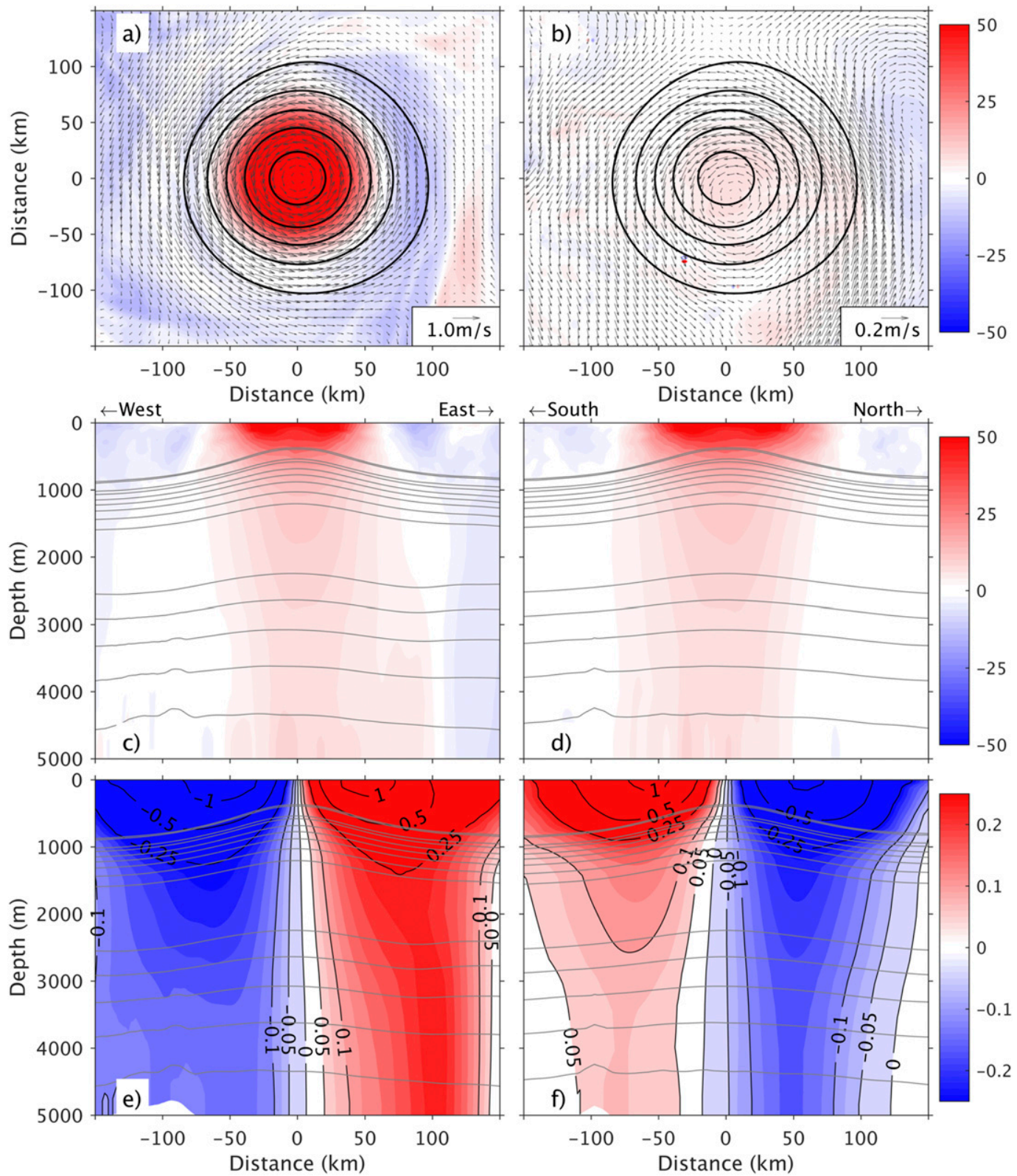

FIG. 16. Structure of a time-averaged Gulf Stream eddy (centered near $36.5^{\circ} \mathrm{N}, 57.5^{\circ} \mathrm{W}$ in Fig. 15), averaged over the period from 1 Aug to $30 \mathrm{Sep}$. The averaging is performed with respect to the eddy center defined by the SSH minimum. The relative vorticity (color shading; with increments of $10^{-6} \mathrm{~s}^{-1}$ ) and horizontal velocities (arrows) near the (a) surface and (b) $4000 \mathrm{~m}$. The black contours are SSH, in 20-cm increments. Vertical slices of the relative vorticity $\left(10^{-6} \mathrm{~s}^{-1}\right)$ in the (c) zonal and (d) meridional directions through the eddy center. Vertical slices of (e) meridional and (f) zonal velocity $\left(\mathrm{m} \mathrm{s}^{-1}\right)$ in the zonal and meridional directions. The gray lines in (c)-(f) denote the model isopycnic layer interfaces (the top 15 layers are not shown).

A number of previous studies have suggested that baroclinic instability is the likely energy source for eddies in the Gulf Stream (Hogg 1985; Cronin and Watts 1996), the Kuroshio (Usui et al. 2008; Bishop et al. 2013), and the ACC (Phillips and Rintoul 2000; Watts et al. 2016). However, these conclusions were based in part on heat fluxes, which can be problematic as a result of difficulties in extracting the dynamically important divergent component (Marshall and Shutts 1981; FoxKemper et al. 2003). But other studies are more in line with lateral instability. Hall (1986) found that barotropic energy conversion (deduced from current meter data at 
$\left.68^{\circ} \mathrm{W}\right)$ is almost twice as strong as baroclinic conversion and occurs primarily in the upper $1000 \mathrm{~m}$. Hall also noted that thermocline stretching is the dominant driving term in the deep vorticity balance. Dewar and Bane (1989) found that conversion from mean kinetic energy dominates that from potential energy at the surface at $73^{\circ} \mathrm{W}$. And in their study of data from the SYNOP experiment, Savidge and Bane (1999b) concluded that the cyclones developing below Gulf Stream meanders differed from atmospheric cyclones in that the intensifying pressure was not linked to density advection. Rather, the cyclones were forced by divergence associated with a deflected thermocline, the same dynamic occurring in the strong topographic cases discussed here.

In order for lateral instability to occur, the currents must be narrower than about four deformation radii. It can be difficult to assess the width of actual currents, due to their meandering, but estimates can be made by averaging in a stream-centered frame. The Gulf Stream appears to be $80-100 \mathrm{~km}$ wide (Halkin and Rossby 1985), roughly 3 times the deformation radius. The Kuroshio is also approximately this wide (Kaneko et al. 1992), and the deformation radius in the region is also of order $30 \mathrm{~km}$ (Chelton et al. 1998). The situation is less clear with the ACC with its multiple jets, but repeat ADCP sections across the Southern Ocean reveal features that are also roughly $100 \mathrm{~km}$ wide (Lenn et al. 2007). However, these measurements were made near $60^{\circ} \mathrm{S}$, where the deformation radius is only $10-20 \mathrm{~km}$. So the ACC is perhaps the most marginal of the three jets in terms of lateral instability. Nevertheless, all three exhibit meanders with wavelengths of several hundred kilometers, in line with a laterally unstable jet $100 \mathrm{~km}$ wide.

Our linear stability analysis, based on the QG equations, does neglect several potentially important phenomena. One is surface fronts (e.g., Thomas et al. 2013). Lateral instability in the presence of a surface front would result in lateral density advection and hence baroclinic instability. An example of this, in the context of the continental slope, was discussed recently by Wang and Stewart (2018). Likewise, the heat fluxes measured by Watts et al. (2016) occurred primarily in the upper $1000 \mathrm{~m}$ of the ACC. But the instability could still be surface trapped. Ribstein and Zeitlin (2013) investigated how a bottom slope affects a pair of surface density fronts in a shallow water system. When the lower layer was deeper than the surface layer, the fastestgrowing mode involved a coupling of disturbances on the surface fronts, which resembles lateral instability in the present examples.

Quantitative aspects could differ nevertheless with finite Rossby number flows (e.g., Bouchut et al. 2011). The intensification of deep cyclones beneath the Gulf
Stream troughs appears to be an ageostrophic effect, as noted. And Gula and Zeitlin (2014) found that the unstable eddies over a slope increased in scale at larger Rossby numbers. Finite-amplitude topography could also impact stability. The $1 \%$ slope required to suppress instability is at the limit of the validity of QG, suggesting a model with higher-order dynamics should be used. And further complications will occur if the fluid interface strikes the bottom (Brink 2012).

Even within the confines of QG though, more work needs to be done. The present formalism only permits one dimensional topography (ridges), but the situation with two dimensional relief could be more complicated, as this permits scattering to different wavelengths. We are currently studying this, using alternate methods. Continuous stratification could also alter the bottom influence, as the flow associated with different size bumps will have different vertical scales (in line with topographic wave scaling). Including a nonparallel planetary beta could alter both the instability and the vertical structure, as noted by Chen and Kamenkovich (2013). And, perhaps most importantly, nonlinearity is likely to impact the results, as energy cascades strongly affect topographic interactions (Herring 1977; Rhines 1977). All such issues need to be addressed.

Acknowledgments. Thanks to Navid Constantinou, Paal Erik Isachsen, and Bill Young for useful discussions and to two anonymous reviewers for constructive comments. JHL was supported in part by the Norwegian Research Council Project 231716, jetSTREAM. EPC and XX were supported by the Office of Naval Research (Grant N00014-15-1-2594) and the NSF Physical Oceanography Program (Award 1537136). Toshiya Fujiwara (JAMSTEC, Japan) kindly provided the bathymetric grids compiled by the Hydrographic and Oceanographic Department, Japan Coast Guard, and JAMSTEC.

\section{REFERENCES}

Ambe, D., S. Imawaki, H. Uccida, and K. Ichikawa, 2004: Estimating the Kuroshio axis south of Japan using combination of satellite altimetry and drifting buoys. J. Oceanogr., 60, 375382, https://doi.org/10.1023/B:JOCE.0000038343.31468.fe.

Andres, M., J. Toole, D. Torres, W. Smethie, T. Joyce, and R. Curry, 2016: Stirring by deep cyclones and the evolution of Denmark Strait Overflow Water observed at line W. Deep-Sea Res. I, 109, 10-26, https://doi.org/10.1016/j.dsr.2015.12.011.

Benilov, E. S., 2001: Baroclinic instability of two-layer flows over one-dimensional bottom topography. J. Phys. Oceanogr., 31, 2019-2025, https://doi.org/10.1175/1520-0485(2001)031<2019: BIOTLF $>2.0 . \mathrm{CO} ; 2$

Bickley, W., 1937: The plane jet. London Edinburgh Dublin Philos. Mag. J. Sci., 23, 727-731, https://doi.org/10.1080/14786443708561847.

Bishop, S., D. Watts, and K. Donohue, 2013: Divergent eddy heat fluxes in the Kuroshio extension at $144^{\circ}-148^{\circ} \mathrm{E}$. Part I: Mean 
structure. J. Phys. Oceanogr., 43, 1533-1550, https://doi.org/ 10.1175/JPO-D-12-0221.1.

Bleck, R., 2002: An oceanic general circulation model framed in hybrid isopycnic-Cartesian coordinates. Ocean Modell., 4, 5588, https://doi.org/10.1016/S1463-5003(01)00012-9.

Blumsack, S. L., and P. J. Gierasch, 1972: The effects of topography on baroclinic instability. J. Atmos. Sci., 29, 1081-1089, https:// doi.org/10.1175/1520-0469(1972)029<1081:MTEOTO > 2.0.CO;2.

Bobrovich, A., and G. Reznik, 1999: Planetary waves in a stratified ocean of variable depth. Part 2. Continuously stratified ocean. J. Fluid Mech., 388, 147-169, https://doi.org/10.1017/S0022112099004863.

Bouchut, F., B. Ribstein, and V. Zeitlin, 2011: Inertial, barotropic, and baroclinic instabilities of the Bickley jet in two-layer rotating shallow water model. Phys. Fluids, 23, 126601, https:// doi.org/10.1063/1.3661995.

Bower, A., and N. Hogg, 1996: Structure of the Gulf Stream and its recirculations at $55^{\circ} \mathrm{W}$. J. Phys. Oceanogr., 26, 1002-1022, https:// doi.org/10.1175/1520-0485(1996)026<1002:SOTGSA > 2.0.CO;2.

Brink, K., 2012: Baroclinic instability of an idealized tidal mixing front. J. Mar. Res., 70, 661-688, https://doi.org/10.1357/ 002224012805262716.

Callies, J., R. Ferrari, J. Klymak, and J. Gula, 2015: Seasonality in submesoscale turbulence. Nat. Commun., 6, 6862, https:// doi.org/10.1038/ncomms7862.

Charney, J. G., 1947: The dynamics of long waves in a baroclinic westerly current. J. Meteor., 4, 136-162, https://doi.org/10.1175/ 1520-0469(1947)004<0136:TDOLWI >2.0.CO;2.

— , and M. E. Stern, 1962: On the stability of internal baroclinic jets in a rotating atmosphere. J. Atmos. Sci., 19, 159-172, https://doi.org/10.1175/1520-0469(1962)019<0159:OTSOIB > 2.0.CO;2.

_ , and G. R. Flierl, 1981: Oceanic analogues of large-scale atmospheric motions. Evolution of Physical Oceanography, C. Wunsch and B. Warren, Eds., MIT Press, 266-290.

Chassignet, E., and $\mathrm{X}$. Xu, 2017: Impact of horizontal resolution $\left(1 / 12^{\circ}\right.$ to $\left.1 / 50^{\circ}\right)$ on Gulf Stream separation, penetration, and variability. J. Phys. Oceanogr., 47, 1999-2021, https://doi.org/ 10.1175/JPO-D-17-0031.1.

_ , L. T. Smith, G. R. Halliwell, and R. Bleck, 2003: North Atlantic simulation with the Hybrid Coordinate Ocean Model (HYCOM): Impact of the vertical coordinate choice, reference density, and thermobaricity. J. Phys. Oceanogr., 33, 2504-2526, https://doi.org/10.1175/1520-0485(2003)033<2504: NASWTH $>2.0 . \mathrm{CO} ; 2$

Chelton, D., R. Deszoeke, M. Schlax, K. El Naggar, and N. Siwertz, 1998: Geographical variability of the first baroclinic Rossby radius of deformation. J. Phys. Oceanogr., 28, 433-460, https:// doi.org/10.1175/1520-0485(1998)028<0433:GVOTFB > 2.0.CO;2.

Chen, C., and I. Kamenkovich, 2013: Effects of topography on baroclinic instability. J. Phys. Oceanogr., 43, 790-804, https:// doi.org/10.1175/JPO-D-12-0145.1.

Cronin, M., and D. Watts, 1996: Eddy-mean flow interaction in the Gulf Stream at $68^{\circ} \mathrm{W}$. Part I: Eddy energetics. J. Phys. Oceanogr., 26, 2107-2131, https://doi.org/10.1175/1520-0485(1996) 026<2107:EFIITG > 2.0.CO;2.

Cushman-Roisin, B., and J. Beckers, 2011: Introduction to Geophysical Fluid Dynamics: Physical and Numerical Aspects. Academic Press, 875 pp.

de La Lama, M. S., J. H. LaCasce, and H. Fuhr, 2016: The vertical structure of ocean eddies. Dyn. Stat. Climate Syst., 1, DZW001, https://doi.org/10.1093/climsys/dzw001.

Dewar, W., and J. Bane, 1989: Gulf Stream dynamics. Part II: Eddy energetics at $73^{\circ} \mathrm{W}$. J. Phys. Oceanogr., 19, 1574-1587,
https://doi.org/10.1175/1520-0485(1989)019<1574:GSDPIE > 2.0.CO;2.

Dubois, N., and N. C. Mitchell, 2012: Large-scale sediment redistribution on the equatorial Pacific seafloor. Deep-Sea Res. I, 69, 51-61, https://doi.org/10.1016/j.dsr.2012.07.006.

Eady, E., 1949: Long waves and cyclone waves. Tellus, 1, 33-52, https://doi.org/10.3402/tellusa.v1i3.8507.

Flierl, G. R., 1999: Thin jet and contour dynamics models of Gulf Stream meandering. Dyn. Atmos. Oceans, 29, 189-215, https:// doi.org/10.1016/S0377-0265(99)00006-8.

- P. Malanotte-Rizzoli, and N. Zabusky, 1987: Nonlinear waves and coherent vortex structures in barotropic beta-plane jets. J. Phys. Oceanogr., 17, 1408-1438, https://doi.org/10.1175/ 1520-0485(1987)017<1408:NWACVS >2.0.CO;2.

Foldvik, A., K. Aagaard, and T. Tørresen, 1988: On the velocity field of the East Greenland Current. Deep-Sea Res., 35A, 1335-1354, https://doi.org/10.1016/0198-0149(88)90086-6.

Fox-Kemper, B., R. Ferrari, and J. Pedlosky, 2003: On the indeterminacy of rotational and divergent eddy fluxes. J. Phys. Oceanogr., 33, 478-483, https://doi.org/10.1175/1520-0485(2003) $033<0478$ :OTIORA $>2.0 . \mathrm{CO} ; 2$.

Gill, A. E., J. Green, and A. Simmons, 1974: Energy partition in the large-scale ocean circulation and the production of mid-ocean eddies. Deep-Sea Res. Oceanogr. Abstr., 21, 499-528, https:// doi.org/10.1016/0011-7471(74)90010-2.

Goff, J., and B. Arbic, 2010: Global prediction of abyssal hill roughness statistics for use in ocean models from digital maps of paleo-spreading rate, paleo-ridge orientation, and sediment thickness. Ocean Modell., 32, 36-43, https://doi.org/10.1016/ j.ocemod.2009.10.001.

Gula, J., and V. Zeitlin, 2014: Instabilities of shallow-water flows with vertical shear in the rotating annulus. Modeling Atmospheric and Oceanic Fluid Flows: Insights from Laboratory Experiments, T. von Larcher and P. D. Williams, Eds., Amer. Geophys. Union, 119-138.

Halkin, D., and T. Rossby, 1985: The structure and transport of the Gulf Stream at $73^{\circ} \mathrm{W}$. J. Phys. Oceanogr., 15, 1439-1452, https://doi.org/10.1175/1520-0485(1985)015<1439:TSATOT> 2.0.CO;2

Hall, M. M., 1986: Assessing the energetics and dynamics of the Gulf Stream at $68 \mathrm{~W}$ from moored current measurements. J. Mar. Res., 44, 423-443, https://doi.org/10.1357/002224086788403033.

Hart, J. E., 1975: Baroclinic instability over a slope. Part 1: Linear theory. J. Phys. Oceanogr., 5, 625-633, https://doi.org/10.1175/ 1520-0485(1975)005<0625:BIOASP $>2.0 . \mathrm{CO} ; 2$.

Herring, J. R., 1977: On the statistical theory of two-dimensional topographic turbulence. J. Atmos. Sci., 34, 1731-1750, https:// doi.org/10.1175/1520-0469(1977)034<1731:OTSTOT>2.0.CO;2.

Hogg, N. G., 1981: Topographic waves along $70^{\circ} \mathrm{W}$ an the continental rise. J. Mar. Res., 39, 627-649.

1985: Evidence for baroclinic instability in the Gulf Stream recirculation. Prog. Oceanogr., 14, 209-229, https://doi.org/ 10.1016/0079-6611(85)90012-6.

Holton, J., 2004: An Introduction to Dynamic Meteorology. 4th ed. Academic Press, 553 pp.

Ikeda, M., 1983: Linear instability of a current flowing along a bottom slope using a three-layer model. J. Phys. Oceanogr., 13, 208-223, https://doi.org/10.1175/1520-0485(1983)013<0208: LIOACF $>2.0 . \mathrm{CO} ; 2$.

Isachsen, P., 2011: Baroclinic instability and eddy tracer transport across sloping bottom topography: How well does a modified Eady model do in primitive equation simulations? Ocean Modell., 39, 183-199, https://doi.org/10.1016/j.ocemod.2010.09.007. 
Jaroslow, G., and B. Tucholke, 1994: Mesozoic-Cenozoic sedimentation in the Kane Fracture Zone, western North Atlantic, and uplift history of the Bermuda Rise. Geol. Soc. Amer. Bull., 106, 319-337, https://doi.org/10.1130/0016-7606(1994)106<0319: MCSITK $>2.3 . C O ; 2$.

Johns, W., T. Shay, J. Bane, and D. Watts, 1995: Gulf Stream structure, transport, and recirculation near $68^{\circ} \mathrm{W}$. J. Geophys. Res., 100, 817-838, https://doi.org/10.1029/94JC02497.

Kaneko, S., S. Mizuno, W. Koterayama, and R. Gordon, 1992: Cross-stream velocity structures and their downstream variation of the Kuroshio around Japan. Deep-Sea Res., 39A, 15831594, https://doi.org/10.1016/0198-0149(92)90049-Y.

Kuo, H., 1949: Dynamic instability of two-dimensional nondivergent flow in a barotropic atmosphere. J. Meteor., 6, 105-122, https:// doi.org/10.1175/1520-0469(1949)006<0105:DIOTDN >2.0.CO;2.

LaCasce, J. H., 2005: Statistics of low frequency currents over the western Norwegian shelf and slope I: Current meters. Ocean Dyn., 55, 213-221, https://doi.org/10.1007/s10236-005-0021-6.

_ 2017: The prevalence of oceanic surface modes. Geophys. Res. Lett., 44, 11 097-11 105, https://doi.org/10.1002/2017GL075430.

Lambaerts, J., G. Lapeyre, and V. Zeitlin, 2012: Moist versus dry baroclinic instability in a simplified two-layer atmospheric model with condensation and latent heat release. J. Atmos. Sci., 69, 1405-1426, https://doi.org/10.1175/JAS-D-11-0205.1.

Lenn, Y., T. Chereskin, J. Sprintall, and E. Firing, 2007: Mean jets, mesoscale variability and eddy momentum fluxes in the surface layer of the Antarctic Circumpolar Current in Drake Passage. J. Mar. Res., 65, 27-58, https://doi.org/10.1357/ 002224007780388694.

Luyten, J., 1977: Scales of motion in the deep Gulf Stream and across the continental rise. J. Mar. Res., 35, 49-74.

Macdonald, K., P. Fox, R. Alexander, R. Pockalny, and P. Gente, 1996: Volcanic growth faults and the origin of Pacific abyssal hills. Nature, 380, 125-129, https://doi.org/10.1038/380125a0.

Marshall, J., and G. Shutts, 1981: A note on rotational and divergent eddy fluxes. J. Phys. Oceanogr., 11, 1677-1680, https://doi.org/ 10.1175/1520-0485(1981)011<1677:ANORAD>2.0.CO;2.

Maslowe, S., 1991: Barotropic instability of the Bickley jet. J. Fluid Mech., 229, 417-426, https://doi.org/10.1017/S0022112091003087.

Mechoso, C., 1980: Baroclinic instability of flows along sloping boundaries. J. Atmos. Sci., 37, 1393-1399, https://doi.org/ 10.1175/1520-0469(1980)037<1393:BIOFAS > 2.0.CO;2.

— horizontal shear along topography. J. Phys. Oceanogr., 11, 813-821, https://doi.org/10.1175/1520-0485(1981)011<0813: IOBFWH $>2.0 . \mathrm{CO} ; 2$.

Menard, H., and J. Mammerickx, 1967: Abyssal hills, magnetic anomalies, and the East Pacific Rise. Earth Planet. Sci. Lett., 2, 465-472, https://doi.org/10.1016/0012-821X(67)90191-4.

Moore, J. K., M. R. Abbot, and J. G. Richman, 1999: Location and dynamics of the Antarctic Polar Front from satellite sea surface temperature data. J. Geophys. Res., 104, 3059-3073, https://doi.org/10.1029/1998JC900032.

Mysak, L., and F. Schott, 1977: Evidence for baroclinic instability of the Norwegian Current. J. Geophys. Res., 82, 2087-2095, https://doi.org/10.1029/JC082i015p02087.

Olive, J.-A., M. Behn, G. Ito, W. Buck, J. Escartin, and S. Howell, 2015: Sensitivity of seafloor bathymetry to climate-driven fluctuations in mid-ocean ridge magma supply. Science, $\mathbf{3 5 0}$, 310-313, https://doi.org/10.1126/science.aad0715.

Orlanski, I., 1969: The influence of bottom topography on the stability of jets in a baroclinic fluid. J. Atmos. Sci., 26, 1216-1232, https:// doi.org/10.1175/1520-0469(1969)026<1216:TIOBTO>2.0.CO;2.
Pedlosky, J., 1964: The stability of currents in the atmosphere and the ocean: Part I. J. Atmos. Sci., 21, 201-219, https://doi.org/ 10.1175/1520-0469(1964)021<0201:TSOCIT>2.0.CO;2.

_ 1987: Geophysical Fluid Dynamics. 2nd ed. Springer-Verlag, 728 pp.

Phillips, H. E., and S. R. Rintoul, 2000: Eddy variability and energetics from direct current measurements in the Antarctic Circumpolar Current south of Australia. J. Phys. Oceanogr., 30, 3050-3076, https://doi.org/10.1175/1520-0485(2000)030<3050: EVAEFD $>2.0 . \mathrm{CO} ; 2$.

Phillips, N. A., 1954: Energy transformations and meridional circulations associated with simple baroclinic waves in a twolevel, quasi-geostrophic model. Tellus, 6, 273-286, https:// doi.org/10.1111/j.2153-3490.1954.tb01123.x.

Pichevin, T., 1998: Baroclinic instability in a three layer flow: A wave approach. Dyn. Atmos. Oceans, 28, 179-204, https:// doi.org/10.1016/S0377-0265(98)00049-9.

Pickart, R., 1995: Gulf Stream-generated topographic Rossby waves. J. Phys. Oceanogr., 25, 574-586, https://doi.org/10.1175/ 1520-0485(1995)025<0574:GSTRW > 2.0.CO;2.

Poulin, F., and G. Flierl, 2003: The nonlinear evolution of barotropically unstable jets. J. Phys. Oceanogr., 33, 2173-2192, https:// doi.org/10.1175/1520-0485(2003)033<2173:TNEOBU>2.0.CO;2.

Renault, L., M. J. Molemaker, J. Gula, S. Masson, and J. C. McWilliams, 2016: Control and stabilization of the Gulf Stream by oceanic current interaction with the atmosphere. J. Phys. Oceanogr., 46, 3439-3453, https://doi.org/10.1175/ JPO-D-16-0115.1.

Rhines, P., 1970: Edge-, bottom-, and Rossby waves in a rotating stratified fluid. Geophys. Astrophys. Fluid Dyn., 1, 273-302, https://doi.org/10.1080/03091927009365776.

, 1977: The dynamics of unsteady currents. Marine Modeling, C. Wunsch et al., Eds., The Sea-Ideas and Observations on Progress in the Study of the Seas, Vol. 6, John Wiley and Sons, 189-318.

Ribstein, B., and V. Zeitlin, 2013: Instabilities of coupled density fronts and their nonlinear evolution in the two-layer rotating shallowwater model: Influence of the lower layer and of the topography. J. Fluid Mech., 716, 528-565, https://doi.org/10.1017/jfm.2012.556.

Richardson, M. J., M. Wimbush, and L. Mayer, 1981: Exceptionally strong near-bottom flows on the continental rise of Nova Scotia. Science, 213, 887-888, https://doi.org/10.1126/ science.213.4510.887.

Richardson, P., 1983: Eddy kinetic energy in the North Atlantic from surface drifters. J. Geophys. Res., 88, 4355-4367, https:// doi.org/10.1029/JC088iC07p04355.

- 1985: Average velocity and transport of the Gulf Stream near 55W. J. Mar. Res., 43, 83-111, https://doi.org/10.1357/ 002224085788437343.

Rona, P., R. Harbison, and S. Bush, 1974: Abyssal hills of the eastern central North Atlantic. Mar. Geol., 16, 275-292, https://doi.org/10.1016/0025-3227(74)90069-3.

Ryan, W., and Coauthors, 2009: Global multi-resolution topography synthesis. Geochem. Geophys. Geosyst., 10, Q03014, https://doi.org/10.1029/2008GC002332.

Samelson, R. M., 1992: Surface-intensified Rossby waves over rough topography. J. Mar. Res., 50, 367-384, https://doi.org/ 10.1357/002224092784797593.

Savidge, D., and J. Bane, 1999a: Cyclogenesis in the deep ocean beneath the Gulf Stream: 1. Description. J. Geophys. Res., 104, 18111-18126, https://doi.org/10.1029/1999JC900132.

_, and - 1999b: Cyclogenesis in the deep ocean beneath the Gulf Stream: 2. Dynamics. J. Geophys. Res., 104, 18127 18140, https://doi.org/10.1029/1999JC900131. 
Schmitz, J. J., 1984: Abyssal eddy kinetic energy in the North Atlantic. J. Mar. Res., 42, 509-536, https://doi.org/10.1357/ 002224084788505933.

Semtner, A., and Y. Mintz, 1977: Numerical simulation of the Gulf Stream and mid-ocean eddies. J. Phys. Oceanogr., 7, 208-230, https://doi.org/10.1175/1520-0485(1977)007<0208:NSOTGS > 2.0.CO;2.

Smith, K. S., 2007: The geography of linear baroclinic instability in Earth's oceans. J. Mar. Res., 65, 655-683, https://doi.org/ $10.1357 / 002224007783649484$.

Tang, C. M., 1976: The influence of meridionally sloping topography on baroclinic instability and its implications for macroclimate. J. Atmos. Sci., 33, 592-601, https://doi.org/10.1175/ 1520-0469(1976)033<0592:TIOMST > 2.0.CO;2.

Thomas, L., J. Taylor, R. Ferrari, and T. Joyce, 2013: Symmetric instability in the Gulf Stream. Deep-Sea Res. II, 91, 96-110, https://doi.org/10.1016/j.dsr2.2013.02.025.

Thompson, R., and J. Luyten, 1976: Evidence for bottom-trapped topographic Rossby waves from single moorings. Deep-Sea Res., 23, 629-635, https://doi.org/10.1016/0011-7471(76)90005-X.

Trefethen, L. N., 2001: Spectral Methods in MATLAB. SIAM, $184 \mathrm{pp}$.

Tulloch, R., J. Marshall, C. Hill, and K. Smith, 2011: Scales, growth rates, and spectral fluxes of baroclinic instability in the ocean. J. Phys. Oceanogr., 41, 1057-1076, https://doi.org/10.1175/ 2011JPO4404.1.

Usui, N., H. Tsujino, H. Nakano, and Y. Fujii, 2008: Formation process of the Kuroshio large meander in 2004. J. Geophys. Res., 113, C08047, https://doi.org/10.1029/2007JC004675.
Vallis, G. K., 2006: Atmospheric and Oceanic Fluid Dynamics: Fundamental and Large-Scale Circulation. 1st ed. Cambridge University Press, 745 pp.

Vanneste, J., 2003: Nonlinear dynamics over rough topography: Homogeneous and stratified quasi-geostrophic theory. J. Fluid Mech., 474, 299-318, https://doi.org/10.1017/S0022112002002707.

Wang, Y., and A. Stewart, 2018: Eddy dynamics over continental slopes under retrograde winds: Insights from a model intercomparison. Ocean Modell., 121, 1-18, https://doi.org/10.1016/ j.ocemod.2017.11.006.

Watts, D., K. Tracey, K. Donohue, and T. Chereskin, 2016: Estimates of eddy heat flux crossing the Antarctic Circumpolar Current from observations in Drake Passage. J. Phys. Oceanogr., 46, 2103-2122, https://doi.org/10.1175/JPO-D-16-0029.1.

Welsh, E. B., N. G. Hogg, and R. M. Hendry, 1991: The relationship of low-frequency deep variability near the HEBBLE site to Gulf Stream fluctuations. Mar. Geol., 99, 303-317, https:// doi.org/10.1016/0025-3227(91)90046-7.

Wessel, P., 2001: Global distribution of seamounts inferred from gridded Geosat/ERS-1 altimetry. J. Geophys. Res., 106, 1943119441, https://doi.org/10.1029/2000JB000083.

Woodgate, R. A., E. Fahrbach, and G. Rohardt, 1999: Structure and transports of the East Greenland Current at $75^{\circ} \mathrm{N}$ from moored current meters. J. Geophys. Res., 104, 18 059-18 072, https://doi.org/10.1029/1999JC900146.

Wunsch, C., 1997: The vertical partition of oceanic horizontal kinetic energy. J. Phys. Oceanogr., 27, 1770-1794, https:// doi.org/10.1175/1520-0485(1997)027<1770:TVPOOH >2.0. $\mathrm{CO} ; 2$. 